OPEN ACCESS

Edited by:

Christopher Bagwell,

Pacific Northwest National Laboratory

(DOE), United States

Reviewed by:

Ajit Kumar Passari,

National Autonomous University

of Mexico, Mexico

Wasu Pathom-aree,

Chiang Mai University, Thailand

*Correspondence:

Debajit Thakur

debajitthakur@yahoo.co.uk

Specialty section:

This article was submitted to

Microbiotechnology,

a section of the journal

Frontiers in Microbiology

Received: 05 December 2019 Accepted: 13 February 2020

Published: 28 February 2020

Citation:

Borah A and Thakur D (2020)

Phylogenetic and Functional

Characterization of Culturable

Endophytic Actinobacteria Associated

With Camellia spp. for Growth

Promotion in Commercial Tea

Cultivars. Front. Microbiol. 11:318. doi: 10.3389/fmicb.2020.00318

\section{Phylogenetic and Functional Characterization of Culturable Endophytic Actinobacteria Associated With Camellia spp. for Growth Promotion in Commercial Tea Cultivars}

\author{
Atlanta Borah and Debajit Thakur* \\ Microbial Biotechnology Laboratory, Life Sciences Division, Institute of Advanced Study in Science and Technology, \\ Guwahati, India
}

Plant associated endophytic actinobacteria may contribute to plant growth and defense by direct or indirect methods. Our aim was to evaluate the plant growth promoting and antifungal activities of endophytic actinobacteria associated with Camellia spp. and related genera, Eurya to find potent plant growth promoting strains that could be applied in future microbe based bioformulations. We isolated 46 endophytic actinobacteria based on morphological characteristics of the isolates. 16S rRNA gene sequence analysis showed that the strains represented nine actinobacterial genera, Nocardia, Amycolatopsis, Streptomyces, Pseudonocardia, Kribbella, Actinomadura, Microbispora, Rothia and Saccharomonospora. In vitro functional characterization of the isolates for plant growth promoting (PGP) traits revealed many potent PGP isolates such as, SA1 and S43 which showed all the tested PGP traits, i.e., phosphate solubilization, indole-3-acetic acid (IAA), ammonia, siderophore and chitinase production. Out of the 46 endophytic actinobacteria isolates, 21 showed inhibition against atleast one test fungal phytopathogen and, isolates SA25 and SA29 exhibited broad spectrum antifungal activity against all the tested phytopathogens. Most of the endophytic actinobacteria isolates having antifungal activity were positive for the presence of chitinase, NRPS (Non-ribosomal peptides synthetase) or PKS-1 (Polyketide Synthase) gene, suggesting the presence of distinctive mechanisms to inhibit the growth of pathogenic plant fungi. ARDRA (Amplified Ribosomal DNA Restriction analysis) and BOX-PCR fingerprinting analysis of the potent isolates with antagonistic activity grouped the isolates into 5 and 4 separate clusters, respectively. In addition, an assessment using bonitur scale revealed the top ranked isolates based on their PGP and biocontrol traits. Further detection of IAA production by the top ranked actinobacterial isolates namely, SA1, T1LA3 and S85 by using thin-layer chromatography (TLC), high-performance liquid chromatography (HPLC) and liquid chromatography-mass spectrometry (LC-MS) was done. Endophytic actinobacteria isolates, namely, SA1, T1LA3, and SA14 were further tested for their efficacy in promoting the growth of commercial tea clones, namely, TV1, 
TV9, TV18, and TV22 in nursery conditions. All the endophytic isolates tested showed significant differences $(P \leq 0.05)$ in terms of plant growth promoting parameters in the treated plants compared to untreated control and may, thus be, deemed as potential candidates for application in bioformulations for tea growth.

Keywords: 16S rRNA, antagonistic, Camellia spp., endophytic actinobacteria, tea growth promotion

\section{INTRODUCTION}

Endophytic bacteria inhabit plant tissues and can boost plant growth under normal and strenuous environments by aiding plants in uptake of metabolites and by regulating phytohormone levels; improvement of plant health by aiming pathogens and pest with antagonistic metabolites, hydrolytic enzymes and nutrient limitation (Afzal et al., 2019). Endophytes are microbes found within various plant tissues, including roots, stems, leaf, flower, fruits, seeds, pollen in a symbiotic relationship without causing any apparent harm (Zhang et al., 2019). Endophytic actinobacteria are recognized as potential agents for their PGP effects and their role in nutrient uptake in host plants by producing biologically active secondary metabolites that enhance the fitness and resilience of the plants against environmental stress (Dinesh et al., 2017; Singh and Dubey, 2018). Endophytic actinobacteria have drawn a significant interest in the recent years for their ability to produce bioactive secondary metabolites with diverse function (Sathya et al., 2017).

Beneficial endophytic actinobacteria with potential biocontrol characteristics have been previously isolated from diverse plant species, such as tomato (Passari et al., 2016a), cereal crops (Patel et al., 2018), and legumes (Le et al., 2016; Vijayabharathi et al., 2018). Endophytic actinobacteria augment plant growth directly through nutrient solubilization, modulation of hormone levels, nitrogen fixation (Palaniyandi et al., 2013; Golinska et al., 2015; Figueiredo et al., 2017). Endophytic actinobacteria are also known to play a significant role in host plant protection from infectious pathogen by producing bioactive antifungal metabolites (Qin et al., 2011), polymer hydrolyzing enzymes like cellulases, siderophores and chitinase which cause degradation of fungal cell wall aiding in lysis of hyphae and limiting spore germination (Liu et al., 2017). Endophytic actinobacteria are also reported as beneficial to plant health by reducing stress hormone ethylene, with the activity of an enzyme, 1-aminocyclopropane1-carboxylate deaminase (Yoolon et al., 2019) (ACCD) that converts ACC into ethylene.

Camellia sinensis L. commonly known as tea is an essential beverage crop due to its various beneficial uses, such as anti-oxidant, anti-microbial, anti-tumor and anti-inflammatory activity (Hayat et al., 2015). The primary center of origin of tea was South-East Asia adjacent to the Irrawaddy river at the conjunction of North-East India, North Burma, SouthWest China and Tibet provinces (Mondal et al., 2004). In North East (NE) India, Assam is the foremost producer of tea and has high socioeconomic value. The Tea plantations of NE India offer congenial environment, rendering tea crop susceptible to various fungal diseases like blister blight, black rot, branch canker, red rust, root/collar rot etc. necessitating judicious use of chemicals. Natural pathogens, including bacteria and fungi, play a significant role in the production of tea as they may have a negative influence on all stages of growth and development. In addition, the tea plants are perennial shrubs that can grow under varied climatic conditions and is constantly subjected to various environmental stresses, either from excessive soil moisture or moisture deficit (Mukhopadhyay and Mondal, 2017; Hajiboland, 2017). Drought is an important factor that affects various biological processes like membrane integrity, chlorophyll pigment content, osmotic potential adjustment, and photosynthetic activity (Anjum et al., 2011; Li et al., 2017) and subsequently limit growth and development of tea crop.

To date, rhizospheric and endophytic PGP bacteria have been explored and characterized from C. sinensis (Dutta et al., 2015b; Nath et al., 2015; Dutta and Thakur, 2017). However, very few data are available on tea endophytic actinobacteria especially in the North East region of India. Also, the culturable microbial diversity and the PGP potential of endophytic actinobacteria associated with wild/ornamental tea has scarcely been explored. Moreover, the naturally occurring endophytic actinobacteria which are already acclimatized to the environment of the high acidic soil of Assam, presents an underexplored source of potential PGP microbes. Thus, the present study aims largely at pursuing significant endophytic actinobacteria from a variety of wild tea species such as C. sinensis, C. japonica, C. sasanqua, C. rosiflora, C. drupifera, and Eurya japonica, which are grown and maintained in the germplasm preservation plot of Tocklai Tea Research Institute (TTRI), Jorhat, Assam, India with special reference to their disease control and plant growth promoting potential, in order to promote organic, chemical free tea cultivation. Accordingly, the present study was conducted to evaluate endophytic actinobacterial communities associated with different tissue parts of healthy tea plants using phylogenetic, functional, and molecular approach, followed by nursery experiments.

\section{MATERIALS AND METHODS}

\section{Collection of Samples and Endophytic Actinobacteria Isolation}

Healthy wild tea species (C. sinensis, C. japonica, C. sasanqua, C. rosiflora, C. drupifera, and Eurya japonica) were collected from germplasm preservation plot of Tocklai Tea Research Institute (TTRI), Jorhat, Assam, India $\left(26^{\circ} 43^{\prime} 45.9^{\prime \prime} \mathrm{N} ; 94^{\circ} 13^{\prime} 40.4^{\prime \prime} \mathrm{E}\right)$ in three seasons-winter (December- $16^{\circ} \mathrm{C}$ temperature; $79 \%$ humidity; $35.84 \mathrm{~mm}$ rainfall in average), spring (April $-23^{\circ} \mathrm{C}$ temperature; $84 \%$ humidity; $157.56 \mathrm{~mm}$ rainfall in average) and 
summer (June $-27^{\circ} \mathrm{C}$ temperature; $91 \%$ humidity; $411.73 \mathrm{~mm}$ rainfall in average) (Borah et al., 2019).

Plant samples were separated into roots and leaves and washed with tap water to remove any debris. Plant samples were then surface sterilized to remove microbes present on the surface (Schulz et al., 1993). After that, surface sterilized dry plant tissues were crushed and ground aseptically in a mortar-pestle and suspended in $0.8 \% \mathrm{NaCl}(1 \mathrm{~g} / \mathrm{mL})$. To validate the surface sterilization procedure, aliquots of the sterile distilled water used in the final wash was spread on GLM agar media (yeast extract, $3 \mathrm{~g}$; malt extract, $3 \mathrm{~g}$; peptone, $5 \mathrm{~g}$; starch, $10 \mathrm{~g}$; agar, $20 \mathrm{~g}$; distilled water, $1000 \mathrm{~mL} ; \mathrm{pH} 7.4$ ) and examined for bacterial growth after incubation at $28^{\circ} \mathrm{C}$ for 7 days.

If no bacterial growth was observed, the plant tissues were the spread onto five selective isolation media, namely actinomycetes isolation agar, streptomyces agar, International streptomyces project (ISP) medium 3, ISP 7, and starch casein agar (HiMedia, India). The media were supplemented with amphotericin $\mathrm{B}$ (75 $\mu \mathrm{g} / \mathrm{mL})$ and rifampicin $(2.5 \mu \mathrm{g} / \mathrm{mL})$ to inhibit growth of endophytic fungi and bacteria, respectively. The culture plates were incubated for 7 to 21 days at $28^{\circ} \mathrm{C}$ and observed daily for the growth of distinct actinobacterial morphotypic colonies with dry and rough appearance. These colonies were selected and the isolates were sub-cultured on GLM agar medium and stored in $20 \%$ glycerol at $-80^{\circ} \mathrm{C}$ for future use.

\section{Morphological Characterization}

The preliminary characterization of the isolated strains by cultural and morphological characteristics such as aerial and substrate mycelia color, pigment production by the isolated strains were recorded according to the International Streptomyces Project (Shirling and Gottlieb, 1966). Micromorphology of the strains was studied by cover slip insertion method (Williams and Cross, 1971) to observe the spore chain morphology of isolates grown on GLM media for 15 days.

\section{Biocontrol Activity Test Fungal Pathogens}

The isolates were tested for antifungal activity with different fungal phytopathogens such as Poria hypobrunnea (ITCC 4141), Fusarium oxysporum (MTCC 284), Pestalotiopsis theae (ITCC 6599), Exobasidium vexans (ITCC 938), Rhizoctonia solani (MTCC 4633), Nigrospora sphaerica (KJ767520) (Dutta et al., 2015a). The test fungal pathogens were obtained from the Microbial Type Culture Collection (MTCC), Institute of Microbial Technology, Chandigarh, India and Indian Type Culture Collection (ITCC), Indian Agricultural Research Institute, New Delhi, India.

\section{Antifungal Activity}

The antifungal activity of the actinobacterial isolates was assessed against six test fungal pathogens. Actinobacterial isolates were spot inoculated in GLM agar medium using spot inoculation method and incubated at $28^{\circ} \mathrm{C}$ for 7 days. Five days old test pathogens grown in potato dextrose broth (HiMedia) was spread on actinobacteria colonies and incubated at $28^{\circ} \mathrm{C}$ for 5 days. The formed antibiosis zone of inhibition was recorded, and the percentage of inhibition of mycelial growth was determined using the formula:

$$
\text { Inhibition of mycelia growth (\%) }=A-\frac{B}{A} \times 100
$$

Where $\mathrm{A}$ is mycelial growth of fungal pathogen in the absence of antagonists; B is mycelial growth of fungal pathogen in the presence of antagonists.

\section{Plant Growth Promoting Traits Indole-3-Acetic Acid Production}

IAA production was assessed following the protocol of Gordon and Weber (1951) with slight modifications. The endophytic actinobacterial isolates were grown individually in GLM broth medium supplemented with L-tryptophan $(1 \mathrm{mg} / \mathrm{mL})$ at $28^{\circ} \mathrm{C}$ under agitated condition. After 5 days, the grown cultures were subjected to centrifugation at $3500 \mathrm{~g}$ for $7 \mathrm{~min}$, and $100 \mu \mathrm{l}$ of the supernatant was added to 96 well microplate in triplicates. $200 \mu \mathrm{l}$ Salkowski reagent consisting of $1 \mathrm{ml}$ $\mathrm{FeCl}_{3}(0.5 \mathrm{M})$ and $49 \mathrm{ml}$ of $35 \% \mathrm{HClO}_{4}$ was added to the supernatant in a ratio of 2:1 (Reagent: culture supernatant) followed by incubation at room temperature for $25 \mathrm{~min}$. Positive IAA production was indicated by the development of pink or red color and absorbance was recorded at $530 \mathrm{~nm}$ in a multimode reader (Varioskan Flash, Thermo Fisher Scientific, United States). A standard curve was obtained using commercial IAA (Sigma-Aldrich, United States) at different known concentrations $(5,10,20,50,100$, and $150 \mu \mathrm{g} / \mathrm{mL})$ and the concentrations of IAA produced by the actinobacteria isolates were calculated.

\section{Phosphate Solubilization}

Detection of phosphate solubilization was done following the protocol of Katznelson and Bose (2010) with modifications. For primary screening, actinobacterial isolates were spot inoculated on Pikovskaya's agar medium (HiMedia, India) and incubated at $28^{\circ} \mathrm{C}$ for 7 days. Presence of a zone of clearance around the colonies were considered as positive isolates. For quantification, the positive actinobacterial isolates were inoculated in Pikovskaya's broth (HiMedia, India) and incubated at $28^{\circ} \mathrm{C}$ in a shaker incubator for 7 days. The cultures were then centrifuged at $13,000 \mathrm{~g}$ for $10 \mathrm{~min}$ and triplicate aliquots of the supernatant $100 \mu \mathrm{l}$ were added to 96 well microplate. Un-inoculated sterile media was used as negative control. Ammonium molybdate reagent containing $2.5 \%$ ammonium molybdate in $1 \mathrm{~N} \mathrm{H}_{2} \mathrm{SO}_{4}$ and $10 \%$ ascorbic acid was added to the supernatant in a ratio of $1: 1$ (Fiske and Subbarow, 1925). Optical density was obtained, and phosphate solubilizing ability was determined using a standard curve of $\mathrm{KH}_{2} \mathrm{PO}_{4}(10,50,100,150,200,250$, and $300 \mu \mathrm{g} \mathrm{ml}^{-}$) at $650 \mathrm{~nm}$ (Varioskan Flash, Thermo Fisher Scientific, United States).

\section{Siderophore Production}

Detection and quantification of siderophore was carried out using Chrome Azurol S assay (Schwyn and Neilands, 1987; Alexander and Zuberer, 1991). Five days old actinobacterial 
culture grown in GLM media were spotted on CAS (Chrome Azurol S) agar plates and incubated at $28^{\circ} \mathrm{C}$ for 7 days. Positive isolates were detected by the development of orange halos around the actinobacteria colonies. The quantitative measurement of siderophore production by the positive isolates detected during preliminary screening was done following the protocol of CAS-shuttle assay. Actinobacterial isolates grown in GLM broth were centrifuged at $3500 \mathrm{~g}$ for $10 \mathrm{~min}$ and $100 \mu \mathrm{l}$ supernatant was added to 96 well plate along with CAS reagent in a ratio of 1:1. Uninoculated GLM broth with CAS reagent in a ratio of $1: 1$ was used as reference and absorbance was recorded at $630 \mathrm{~nm}$ (Varioskan Flash, Thermo Fisher Scientific, United States). Siderophore production was determined using the formula below (Pal and Gokarn, 2010):

$$
\text { Siderophore }(\%)=\frac{A r-A s}{A r} \times 100
$$

Where, $\mathrm{Ar}=$ absorbance of reference solution and As $=$ absorbance of sample at $630 \mathrm{~nm}$.

\section{Ammonia Production}

For estimation of ammonia production, actinobacterial isolates were grown in peptone water for 7 days at $28^{\circ} \mathrm{C}$. After 7 days, the actinobacteria culture were centrifuged at $3500 \mathrm{~g}$ for $10 \mathrm{~min}$. To $1 \mathrm{ml}$ of the culture supernatant, $50 \mu \mathrm{l}$ of Nessler's reagent [7\% KI; $10 \% \mathrm{HgI}_{2} ; 50 \%$ aqueous solution of $\mathrm{NaOH}(32 \%)]$ (Cappuccino and Sherman, 2014) was added. Development of yellow to brown color indicates the presence of ammonia. The optical density at $450 \mathrm{~nm}$ was determined, and ammonia production by each active isolate was determined using a standard curve of ammonium sulfate solution at different known concentrations of 0.1, 0.5, 1, 1.5, 2, 2.5, 3, 3.5, and $4 \mathrm{umol} / \mathrm{mL} 5$ (Varioskan Flash, Thermo Fisher Scientific, United States).

\section{Extracellular Enzyme Production}

The endophytic actinobacterial isolates were screened for the production of extracellular enzymes, namely, protease, cellulase, pectinase, chitinase and ACC deaminase. The actinobacteria isolates were grown in $50 \mathrm{~mL}$ of GLM broth media at $28^{\circ} \mathrm{C}$ for 7 days under agitated conditions. For detection of proteolytic activity, the actinobacteria isolates were spot inoculated on skim milk agar media plates comprising of (per liter) $2.5 \mathrm{~g}$ yeast extract, $1 \mathrm{~g}$ glucose, $5 \mathrm{~g}$ pancreatic digest of casein, $28 \mathrm{~g}$ skim milk powder and $15 \mathrm{~g}$ agar, followed by incubation at $28^{\circ} \mathrm{C}$ for 7 days. Positive isolates were confirmed by the presence of clear areas around the actinobacteria colony (Kazanas, 1968). Cellulase and pectinase activity was tested by spot inoculation of actinobacteria isolates on M9 minimal salt medium consisting of (per liter) $33.9 \mathrm{~g}$ $\mathrm{Na}_{2} \mathrm{HPO}_{4}, 15 \mathrm{~g} \mathrm{KH}_{2} \mathrm{PO}_{4}, 2.5 \mathrm{~g} \mathrm{NaCl}, 5 \mathrm{~g} \mathrm{NH} \mathrm{N}_{4} \mathrm{Cl}, 15 \mathrm{~g}$ agar, $1.2 \mathrm{~g}$ yeast extract. For screening cellulase producing isolates, the M9 media was amended with $10 \mathrm{~g}$ cellulose and for pectin, the media was amended with pectin $(1 \% \mathrm{w} / \mathrm{v})$. After seven days of incubation at $28^{\circ} \mathrm{C}$, the colonies were flooded with $1 \mathrm{ml}$ of Gram's iodine $(2.0 \mathrm{~g}$ KI and $1.0 \mathrm{~g}$ iodine in $300 \mathrm{ml}$ distilled water) for cellulase producing isolates detection and Congo red $(0.12 \%)$ for pectinase producing isolates detection. Presence of clear zone surrounding the colonies were considered positive (Teather and Wood, 1982; Kasana et al., 2008). Chitinase production was assessed by spot inoculating actinobacteria isolates on M9 minimal salt agar plates containing $1 \% \mathrm{w} / \mathrm{v}$ colloidal chitin and $1.2 \mathrm{~g}$ yeast extract followed by incubation for 7 days at $28^{\circ} \mathrm{C}$. Development of zone of clearance around the colonies were considered as positive for chitinase production (Hsu and Lockwood, 1975). Qualitative assay for ACC deaminase activity was performed by spot inoculation of actinobacterial isolates in Dworkin and Foster (DF) salt medium (Dworkin and Foster, 1958) modified with $3 \mathrm{mM}$ filter sterile, ACC (Onofre-Lemus et al., 2009). Actinobacteria isolates were grown in $50 \mathrm{ml}$ of DF media amended with $3 \mathrm{mM}$ ACC and incubated at $28 \pm 2{ }^{\circ} \mathrm{C}$ under agitated conditions at $200 \mathrm{rev} \mathrm{min}^{-1}$ for 5-7 days. DF agar plates were then spread with $3 \mathrm{mM}$ ACC solution and allowed to dry fully before actinobacterial spot inoculation. The inoculated plates were incubated at $28 \pm 2^{\circ} \mathrm{C}$ for 5 -days and actinobacterial growth was observed.

\section{Assessment of PGP and Biocontrol Traits}

The PGP traits, namely, IAA production, phosphate solubilization, ammonia production, nitrogen fixation, chitinase activity and siderophore production by the endophytic actinobacterial isolates were analyzed and represented as Venn diagram using Vennture software (Martin et al., 2012). Similarly, the biocontrol traits profile of all the endophytic actinobacterial isolates were also represented as Venn diagram using Vennture software (Martin et al., 2012). To select actinobacterial isolates with superior PGP potential, a bonitur scale was generated and applied for the evaluation of PGPR and biocontrol traits similar to that of Passari et al. (2016b). In this scale, points were allocated for each in vitro PGP and biocontrol traits tested. The highest possible bonitur score for the PGP traits is 29 points. A maximum of three points were given to antifungal activity against six tested pathogens depending on percentage of inhibition, leading to a sum of 18 points. IAA production and phosphate solubilization was each given maximum three points depending on the strength of the PGP traits. Siderophore, ammonia production, chitinase and ACC deaminase were assigned one point each.

\section{Phosphate Solubilization Efficiency of the Endophytic Actinobacterial Isolates}

For assessment of phosphate solubilization at different initial $\mathrm{pH}$ (alkaline, neutral and acidic $\mathrm{pH}$ ), three actinobacterial isolates were selected on the basis of Bonitur ranking. The three isolates, SA1, SA14 and S85 were quantitatively tested using colorimetric assay for their efficiency to solubilize phosphate at different initial $\mathrm{pH}$ of $6.0,7.0$ and 8.0 (Marra et al., 2015).

The actinobacterial isolates were inoculated in Pikovskaya's broth (HiMedia, India) and incubated at $28^{\circ} \mathrm{C}$ in a shaker incubator for 7 days. The cultures were then centrifuged at 
$13,000 \mathrm{~g}$ for $10 \mathrm{~min}$ and triplicate aliquots of the supernatant 100 $\mu \mathrm{l}$ were added to 96 well microplate. Un-inoculated sterile media was used as negative control. Ammonium molybdate reagent containing $2.5 \%$ ammonium molybdate in $1 \mathrm{~N} \mathrm{H}_{2} \mathrm{SO}_{4}$ and $10 \%$ ascorbic acid was added to the supernatant in a ratio of 1:1
(Fiske and Subbarow, 1925). Optical density was obtained, and phosphate solubilizing ability was determined using a standard curve of $\mathrm{KH}_{2} \mathrm{PO}_{4}(10,50,100,150,200,250$, and $300 \mu \mathrm{g}$ $\mathrm{ml}^{-}$) at $650 \mathrm{~nm}$ (Varioskan Flash, Thermo Fisher Scientific, United States).

TABLE 1 | Morphological characterization of endophytic actinobacteria associated with tea.

\begin{tabular}{|c|c|c|c|c|c|c|}
\hline SI. No. & Isolate code & Colony morphology & Aerial mycelia color & Substrate mycelia color & Diffusible pigment & Color series \\
\hline 1 & SA1 & Irregular, Raised & Brown & Yellow & ND & Brown \\
\hline 2 & $\mathrm{SA} 2$ & Circular, Flat & Red & Red & Red & Red \\
\hline 3 & T1LA3 & Curled, Convex & White & Orange & Light Pink & White \\
\hline 4 & SA16 & Circular, Crateriform & White & Off White & ND & White \\
\hline 5 & SA6 & Irregular, Raised & White & Yellow & ND & White \\
\hline 6 & CSLA2 & Circular, Crateriform & Yellow & Yellow & ND & White \\
\hline 7 & CJRA1 & Irregular, Raised & Gray & Brown & ND & Gray \\
\hline 8 & S40 & Circular, Umbonate & Off White & Off White & ND & White \\
\hline 9 & SA21 & Circular, Convex & Cream & Cream & ND & White \\
\hline 10 & SA5 & Irregular, Umbonate & Black & Dark Gray & Yellow & Gray \\
\hline 11 & CSLA5 & Irregular, Flat & Yellow & Yellow & ND & White \\
\hline 12 & S51 & Irregular, Flat & White & Gray & ND & Gray \\
\hline 13 & S62 & Irregular, Flat & Brown & Brown & ND & Brown \\
\hline 14 & S28 & Circular, Flat & Light Pink & White & ND & White \\
\hline 15 & T1LA5 & Irregular, Raised & Gray & Black & ND & Gray \\
\hline 16 & S39 & Punctiform & White & Yellow & ND & White \\
\hline 17 & SA13 & Umbonate, Raised & Brown & Brown & ND & White \\
\hline 18 & SA14 & Circular, Umbonate & White & Brown & ND & White \\
\hline 19 & SA9 & Irregular, Raised & Gray & Black & ND & Gray \\
\hline 20 & S41 & Irregular, Raised & Brown & Brown & ND & Brown \\
\hline 21 & S85 & Circular, Umbonate & White & Brown & ND & White \\
\hline 22 & S42 & Irregular, Raised & Off White & Off White & ND & White \\
\hline 23 & SA10 & Irregular, Raised & White & Gray & ND & White \\
\hline 24 & SA20 & Circular, Flat & Yellow & Yellow & ND & White \\
\hline 25 & S84 & Irregular, Umbonate & Light Pink & Peach & ND & White \\
\hline 26 & CJRA5 & Circular, Flat & Light Pink & Off White & ND & Variable \\
\hline 27 & CJRA2 & Irregular, Raised & White & Off White & ND & White \\
\hline 28 & CSLA7 & Circular, Crateriform & Brown & Brown & ND & Variable \\
\hline 29 & CRRA1 & Irregular, Umbonate & Brown & Brown & Brown & Brown \\
\hline 30 & SA7 & Irregular, Flat & Pink & Pink & Pink & Pink \\
\hline 31 & SA8 & Circular, Flat & Gray & Brown & Brown & Gray \\
\hline 32 & SA4 & Irregular, Raised & White & Yellow & Yellow & White \\
\hline 33 & S43 & Circular, Flat & Gray & Black & ND & Gray \\
\hline 34 & $\mathrm{~S} 72$ & Irregular, Raised & Gray & Yellow & ND & White \\
\hline 35 & CSR1 & Circular, Raised & Off White & Off White & ND & White \\
\hline 36 & SA27 & Circular, Crateriform & Peach & Peach & ND & Orange \\
\hline 37 & SA35 & Circular, Raised & White & Cream & ND & White \\
\hline 38 & SA17 & Circular, Flat & Gray & Gray & ND & Gray \\
\hline 39 & SA12 & Irregular, Raised & Peach & Brown & ND & Variable \\
\hline 40 & SA29 & Circular, Crateriform & White & Yellow & ND & White \\
\hline 41 & SA3 & Undulate, Flat & White & Orange & Yellow & White \\
\hline 42 & SA25 & Irregular, Flat & Brown & Brown & Brown & Brown \\
\hline 43 & CSR3 & Irregular, Convex & Light Yellow & Light Yellow & ND & Yellow \\
\hline 44 & CSLA6 & Irregular, Umbonate & Brown & Brown & Brown & Brown \\
\hline 45 & CSR4 & Irregular, Raised & Gray & Dark Pink & Pink & Gray \\
\hline 46 & SA11 & Circular, Crateriform & Light Pink & Yellow & ND & White \\
\hline
\end{tabular}

ND, not detected. 
TABLE 2 | Plant growth promoting and antifungal characteristics of endophytic actinobacteria isolated from tea plants.

\begin{tabular}{|c|c|c|c|c|c|c|c|c|c|c|c|c|}
\hline \multirow[t]{2}{*}{ SI. no. } & \multirow[t]{2}{*}{ Strain code } & \multirow[t]{2}{*}{ IAA $\left(\mu \mathrm{g} \mathrm{ml}^{-1}\right)$} & \multirow{2}{*}{$\begin{array}{l}\text { P solubilization } \\
\left(\mu \mathrm{g} \mathrm{ml}^{-1}\right)\end{array}$} & \multirow{2}{*}{$\begin{array}{c}\text { Ammonia } \\
\left(\mu \mathrm{mol} \mathrm{ml}^{-1}\right)\end{array}$} & \multirow[t]{2}{*}{$\mathrm{N}_{2}$ fixation } & \multirow[t]{2}{*}{ Siderophore (\%) } & \multicolumn{6}{|c|}{ Inhibition of mycelia growth (\%) } \\
\hline & & & & & & & 1 & 2 & 3 & 4 & 5 & 6 \\
\hline 1 & SA1 & $19.0 \pm 4.0$ & $141.1 \pm 17.2$ & $2.9 \pm 0.5$ & + & $30.5 \pm 0.6$ & - & - & - & $75 \pm 1.3$ & $85.7 \pm 1.3$ & $62.7 \pm 1.2$ \\
\hline 2 & SA2 & $14.8 \pm 0.5$ & $107.8 \pm 4.6$ & $5.5 \pm 0.7$ & + & - & - & $62.5 \pm 1.0$ & - & - & - & $78 \pm 2.1$ \\
\hline 3 & T1LA3 & $23.2 \pm 0.2$ & - & $6.5 \pm 0.8$ & - & $12.1 \pm 0.3$ & $86.8 \pm 1.1$ & - & - & $82.5 \pm 1.5$ & $57 \pm 1.1$ & $76.7 \pm 1.6$ \\
\hline 4 & SA16 & $40.7 \pm 0.7$ & $277.5 \pm 14.5$ & $2.1 \pm 1.0$ & + & - & - & - & - & - & - & - \\
\hline 5 & SA6 & $9.2 \pm 0.2$ & - & - & + & - & $75 \pm 1.8$ & - & - & $50 \pm 1.2$ & - & $44 \pm 2.0$ \\
\hline 6 & CSLA2 & $4.4 \pm 0.4$ & - & - & - & - & - & - & - & - & - & - \\
\hline 7 & CJRA1 & $46.5 \pm 0.7$ & - & - & - & - & $54.5 \pm 1.19$ & - & - & - & - & - \\
\hline 8 & S40 & $7.1 \pm 0.1$ & $171.9 \pm 3.0$ & $3.0 \pm 0.8$ & - & - & $34 \pm 1.07$ & - & - & - & - & - \\
\hline 9 & SA21 & - & - & $5.5 \pm 0.4$ & + & - & - & - & $90 \pm 0.9$ & - & - & - \\
\hline 10 & SA5 & - & $171.7 \pm 11.8$ & - & - & - & - & - & - & - & - & - \\
\hline 11 & CSLA5 & - & $142.8 \pm 7.4$ & $2.1 \pm 1.0$ & + & - & - & - & - & - & - & - \\
\hline 12 & S51 & - & - & - & - & - & - & - & - & - & - & - \\
\hline 13 & S62 & $22.9 \pm 0.3$ & $127.9 \pm 20.0$ & $5.3 \pm 0.4$ & + & - & $65 \pm 1.5$ & - & - & $25 \pm 0.5$ & $40 \pm 1.1$ & $25 \pm 0.4$ \\
\hline 14 & S28 & - & - & $3.3 \pm 0.5$ & - & - & - & - & - & - & - & $72 \pm 1.9$ \\
\hline 15 & T1LA5 & - & - & - & - & - & - & - & - & - & - & - \\
\hline 16 & S39 & $19.2 \pm 0.4$ & $216.2 \pm 10.7$ & $2.5 \pm 1.1$ & + & - & - & - & - & - & - & - \\
\hline 17 & SA13 & - & $153.2 \pm 7.7$ & - & - & - & - & - & - & $62.5 \pm 2.4$ & - & $50 \pm 2.3$ \\
\hline 18 & SA14 & - & $219.3 \pm 0.8$ & $3.6 \pm 0.5$ & - & - & $30 \pm 0.2$ & $80 \pm 2.5$ & - & - & $62.8 \pm 2.5$ & $76.7 \pm 1.6$ \\
\hline 19 & SA9 & - & - & - & - & - & - & - & - & - & - & - \\
\hline 20 & S41 & $7.1 \pm 0.2$ & $188.6 \pm 20.1$ & $1.4 \pm 0.1$ & + & - & - & - & - & - & - & - \\
\hline 21 & S85 & $39.0 \pm 0.8$ & $187.2 \pm 14.8$ & - & - & - & $65.9 \pm 1.4$ & $35.4 \pm 1.7$ & - & - & - & $53.4 \pm 1.8$ \\
\hline 22 & $\mathrm{~S} 42$ & $17.6 \pm 0.4$ & $59.1 \pm 5.0$ & - & - & - & - & - & - & - & - & - \\
\hline 23 & SA10 & - & - & - & - & - & - & - & - & - & - & - \\
\hline 24 & SA20 & - & - & - & - & - & - & - & - & - & - & - \\
\hline 25 & S84 & $5.6 \pm 0.3$ & $190.9 \pm 19.9$ & $4.3 \pm 0.3$ & + & - & $25 \pm 1.2$ & - & - & - & - & - \\
\hline 26 & CJRA5 & - & - & - & - & - & - & - & - & - & - & - \\
\hline 27 & CJRA2 & - & - & - & + & - & - & - & - & - & - & - \\
\hline 28 & CSLA7 & - & - & - & - & - & - & - & - & - & - & - \\
\hline 29 & CRRA1 & $7.0 \pm 0.2$ & - & - & - & - & - & $35.4 \pm 1.0$ & - & - & - & - \\
\hline 30 & SA7 & - & $256.4 \pm 13.7$ & $4.4 \pm 0.6$ & + & - & - & - & - & - & - & - \\
\hline 31 & SA8 & $18.8 \pm 0.7$ & - & - & - & - & - & $35.4 \pm 1.6$ & - & - & - & $65.1 \pm 0.9$ \\
\hline 32 & SA4 & $10.5 \pm 1.5$ & - & $1.3 \pm 0.2$ & - & - & - & - & - & - & - & - \\
\hline 33 & S43 & $19.4 \pm 0.4$ & $132.7 \pm 10.9$ & $4.7 \pm 0.6$ & + & $27.0 \pm 0.9$ & - & $41.9 \pm 2.9$ & - & - & - & $62.5 \pm 1.4$ \\
\hline 34 & S72 & - & $135.1 \pm 18.0$ & - & - & - & - & - & - & - & - & - \\
\hline 35 & CSR1 & $10.6 \pm 0.6$ & $183.4 \pm 12.6$ & $2.5 \pm 0.3$ & + & - & - & - & - & - & - & - \\
\hline
\end{tabular}




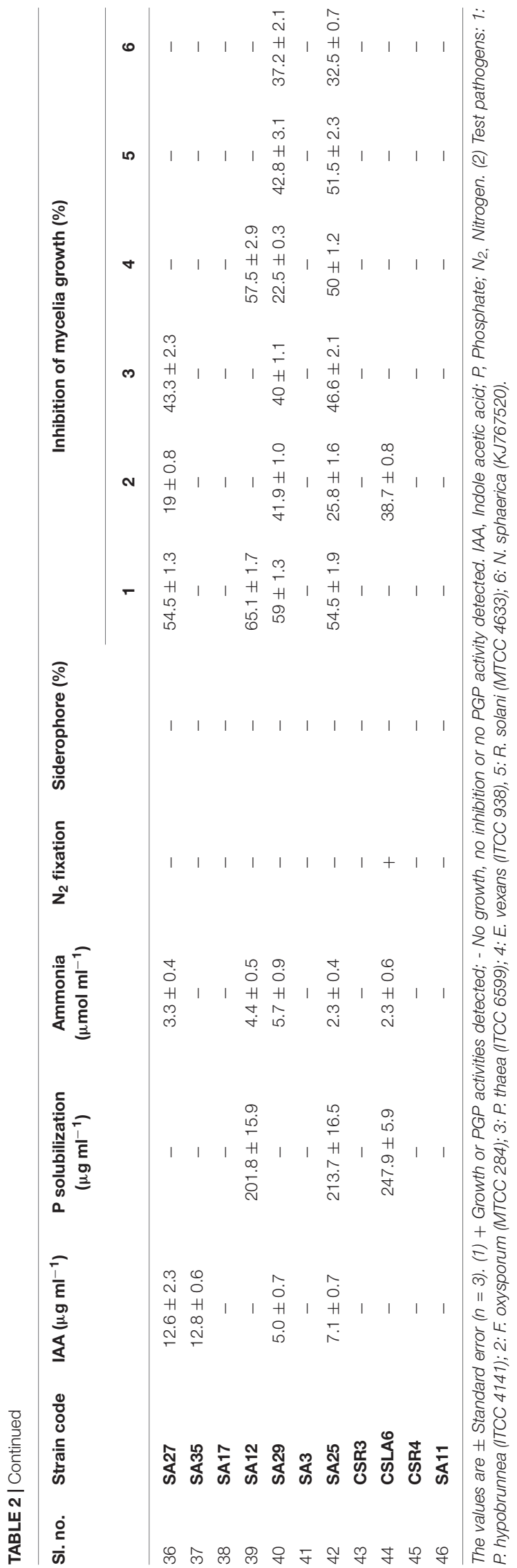

\section{Extraction, Purification, and Determination of IAA \\ Extraction of Crude IAA}

For determination of IAA production, isolates SA1, T1LA3 and S85 were selected on the basis of Bonitur assessment. Actinobacterial colony of these IAA producing isolates were inoculated into $200 \mathrm{ml}$ GLM broth amended with L-tryptophan $(1 \mathrm{mg} / \mathrm{mL})$ and incubated at $28^{\circ} \mathrm{C}$ for 7 days in an orbital-shaking incubator. Bacterial supernatant was then separated from the bacterial cells by centrifugation at $10,000 \mathrm{~g}$ for $20 \mathrm{~min}$, followed by filtration using a Whatman, $0.2 \mu \mathrm{m}$ filter paper to acquire a cell-free supernatant. The supernatant was acidified to $\mathrm{pH} 2.5-3.0$ using $1 \mathrm{~N} \mathrm{HCl}$, extracted with ethyl acetate in a ratio of 1:1 (v/v) by vigorous mixing of the cell free supernatant and separating the organic phase in a separatory funnel (Bharucha et al., 2013). The extracted ethyl acetate fraction was evaporated in a rotary evaporator (Rotavapor R-210, Buchi, Switzerland) at $50^{\circ} \mathrm{C}$. The crude extract was dissolved in $2 \mathrm{ml}$ of methanol and kept at $4^{\circ} \mathrm{C}$ for further tests.

\section{Detection of IAA by Thin Layer Chromatography}

Extracts of crude IAA were plated on pre-coated silica gel 60 $\mathrm{F}_{254}$ TLC plates (Merck, Germany) along with standard IAA (Sigma-Aldrich, United States). The IAA standard was prepared at a concentration of $0.5 \mathrm{mg} / \mathrm{mL}$ in methanol and TLC was performed with a mobile phase of acetone: ethyl acetate: ethanol: water (3:5:1:1 v/v/v/v) (Ahmad et al., 2005). TLC plates were dried and spots with identical RF values to standard IAA were observed under UV light $(254 \mathrm{~nm})$ and developed by spraying with Salkowski reagent.

\section{Detection of IAA by High Performance Liquid Chromatography}

HPLC analysis of the crude ethyl acetate extract was carried out on a Waters HPLC, Breeze 2 (Massachusetts, United States) using a C18 analytical column $(4.6 \mathrm{~mm} \times 250 \mathrm{~mm}, 5 \mu \mathrm{m})$ (ODS2, Waters spherisorb). The column temperature was maintained at $25^{\circ} \mathrm{C}$ and methanol and $1 \%$ acetic acid (50:50 v/v) was used as the mobile phase at a flow rate of $1 \mathrm{~mL} / \mathrm{min}$ with an injection volume of $20 \mu \mathrm{L}$ (Myo et al., 2019). Detection was monitored at $254 \mathrm{~nm}$ and $280 \mathrm{~nm}$, and data were evaluated using Breeze 2 software by comparing with the elution profiles of standard IAA $(0.5 \mathrm{mg} / \mathrm{mL})$ injected separately.

\section{Detection of IAA by Liquid Chromatography-Mass Spectrometry}

An Ultimate 3000 rapid separation LC (Dionex Inc., Sunnyvale, CA, United States) coupled to a Thermo Exactive plus Orbitrap triple quadrupole Mass Spectrometer (Thermo Fisher Scientific, United States) equipped with an electrospray ionization (ESI) interface was used to detect IAA in crude ethyl acetate extract. The chromatographic separation of each sample and standard IAA $(0.5 \mathrm{mg} / \mathrm{mL}$ ) was on a C18 column (Hypersil gold, Dim. $150 \mathrm{~mm} \times 2.1 \mathrm{~mm}, 1.9 \mu \mathrm{m}$ ) (Thermo Fisher Scientific, United States) with $0.1 \%$ formic acid in water (mobile phase A) and methanol (mobile phase B) was used and the column temperature was set at $25^{\circ} \mathrm{C}$. Gradient elution at a flow rate 
of $0.300 \mathrm{~mL} / \mathrm{min}$ was performed. The gradient program was as follows: $0-2.5 \mathrm{~min}$ from 20 to $40 \% \mathrm{~B} ; 2.5-4.0 \mathrm{~min}$ from 40 to $50 \% \mathrm{~B} ; 4.0-5.0 \mathrm{~min}$ from 50 to $98 \% \mathrm{~B} ; 5.0-6.0 \mathrm{~min} 98 \% \mathrm{~A}$ to $2 \% \mathrm{~B}$; and $6.0-8.0 \mathrm{~min} 20 \% \mathrm{~A}$ to $80 \% \mathrm{~B}$. The total run time was $8.0 \mathrm{~min}$, and a volume of $10 \mu \mathrm{L}$ was injected onto the Hypersil C18 gold column by an RS-3000 autosampler (Dionex Inc., Sunnyvale, CA, United States). ESI-MS was performed in both the modes with a spray voltage of $4 \mathrm{kV}$, capillary temperature at $270^{\circ} \mathrm{C}$; auxiliary gas heater temperature, $45^{\circ} \mathrm{C}$, auxiliary gas flow rate at 6 (arbitrary units) and a full scan data were obtained by scanning from $\mathrm{m} / \mathrm{z} 50-750$. The chromatograms for each sample were recorded using a PDA detector and data acquisition and processing were done using the Xcalibur software (Thermo Fisher Scientific, United States).

\section{Biochemical Profile of Top Ranked Isolates}

Biochemical characterization of the highest bonitur ranked three isolates was performed with a number of tests, including carbohydrate utilization, $\beta$-galactosidase activity, esculin hydrolysis, citrate and malonate utilization. The tests were performed using KB009 HiCarbohydrate kit (HiMedia, India). Actinobacterial isolates grown in GLM broth were centrifuged at $3500 \mathrm{~g}$ and the cells were washed and resuspended in saline solution $(0.9 \% \mathrm{NaCl})$. Each of the wells of the kit was inoculated with $50 \mu \mathrm{l}$ of the actinobacterial suspension by surface inoculation method and incubated at $28^{\circ} \mathrm{C}$ for $4-7$ days. Changes in the color of the medium were recorded.

\section{Fungal Hyphal Morphology of $P$. hypobrunnea as Affected by Isolate T1LA3}

Test fungal pathogen, $P$. hypobrunnea was co-inoculated with endophytic actinobacteria isolate, T1LA3 in PDA media at $28^{\circ} \mathrm{C}$ for 10 days. Fungal mycelia of plant pathogen, P. hypobrunnea grown on PDA plate along with actinobacterial isolate, T1LA3 from the edge of zone of inhibition were mounted on glass slides for lactophenol cotton blue staining and observed under a light microscope (100X with oil suspension; Motic BA410).

\section{Phylogenetic Characterization Genomic DNA Extraction and 16S rRNA Gene Amplification}

Genomic DNA was extracted from the actinobacterial strains using Nucleopore Fungus/bacteria kit (Genetix, India). 16S rRNA gene amplification was done using universal primers $27 \mathrm{~F}\left(5^{\prime}\right.$ AGA GTT TGA TCC TGG CTC AG-3') and 1492 R (5'-GGT TAC CTT GTT ACG ACT T- $3^{\prime}$ ) as previously described (Hongoh et al., 2003) in $50 \mu \mathrm{l}$ reaction mixture containing $0.2 \mu \mathrm{M}$ of each primer, $0.2 \mathrm{mM}$ of each dNTP, 1X Taq buffer, $1.5 \mathrm{mM} \mathrm{MgCl}_{2}$, $1 \mathrm{U}$ TaqDNA polymerase (TaKaRa Bio Inc., Japan) and 50 ng of template DNA. The PCR cycle was carried out in a Mastercycler nexus PCR system (Eppendorf, Germany) and the cycle consisted of initial denaturation $\left(94^{\circ} \mathrm{C}\right.$ for $\left.5 \mathrm{~min}\right), 35$ cycles of denaturation $\left(94^{\circ} \mathrm{C}\right.$ for $30 \mathrm{~s}, 52^{\circ} \mathrm{C}$ for $30 \mathrm{~s}, 72^{\circ} \mathrm{C}$ for $\left.1 \mathrm{~min}\right)$, annealing $\left(72^{\circ} \mathrm{C}\right.$ for $1 \mathrm{~min})$ and final extension $\left(72^{\circ} \mathrm{C}\right.$ for $\left.1 \mathrm{~min}\right)$. Then, the amplified products were subjected to gel electrophoresis using a $1.5 \%$ agarose gel stained with $\mathrm{EtBr}(10 \mu \mathrm{g} / \mathrm{mL})$ at $70 \mathrm{~V}$ for $45 \mathrm{~min}$ and visualized in a gel documentation system (Bio Rad ChemiDoc
XRS +). The PCR amplified products were then sent to DNA sequencing services (1st BASE DNA Sequencing Services, Base Asia) for Sanger sequencing.

\section{Amplified Ribosomal DNA Restriction Analysis}

The potent endophytic actinobacterial isolates showing positive antifungal activity were subjected to Amplified ribosomal DNA restriction analysis (ARDRA). The amplified $16 \mathrm{~S}$ rRNA were subjected to restriction digestion using $2 \mathrm{U}$ of each of the enzymes HinfI, KpnI, Sau3A1, HaeIII, and HindI (New England Biolabs, United Kingdom) as manufacturer's recommendation. The digestion was done in $25 \mu \mathrm{l}$ reaction mixture and incubated at $37^{\circ} \mathrm{C}$ for $2 \mathrm{~h}$ followed by heat inactivation at $70^{\circ} \mathrm{C}$ for $10 \mathrm{~min}$. Each digested sample mixed with $4 \mu \mathrm{l}$ 6X loading dye was subjected to $2 \%$ agarose gel electrophoresis at $70 \mathrm{~V}$ for $3 \mathrm{~h}$ along with $100 \mathrm{bp}$ DNA ladder and visualized in a gel documentation system (ChemiDoc XRS +, Bio-Rad, United States) and analyzed by NTSYS-pc version 2.02. software (Applied Biostatistics Inc., New York).

\section{BOX-PCR}

The potent endophytic actinobacterial isolates showing positive antifungal activity were subjected to genotypic analysis by rep-PCR fingerprinting using BOX-A1R primer (5'-CTACGGCAAGGCGACGCTGACG-3') (Smith et al., 2001). PCR amplification was carried out in $25 \mu$ l volume containing $1 \mathrm{X}$ Taq buffer, $0.1 \mathrm{U}$ Taq polymerase, $2.5 \mathrm{mM}$ each deoxynucleotide triphosphate (dNTP), $1.5 \mathrm{mM} \mathrm{MgCl}_{2}, 2.5 \mathrm{mM}$ of BOX-A1R primer and $10 \mathrm{ng}$ DNA template under the following conditions: $1 \mathrm{~min}$ at $94^{\circ} \mathrm{C}, 35$ cycles at $94^{\circ} \mathrm{C}, 55^{\circ} \mathrm{C}$ for 1 min each and $72^{\circ} \mathrm{C}$ for $1.5 \mathrm{~min}$ and final extension at $72^{\circ} \mathrm{C}$ for $7 \mathrm{~min}$ (Lee et al., 2014). The PCR products along with $100 \mathrm{bp}$ DNA ladder (TaKaRa Bio Inc., Japan) were subjected to $2 \%$ agarose gel electrophoresis and visualized using a gel documentation system (ChemiDoc XRS +, Bio-Rad, United States) followed by analysis using Phoretix 1D Pro gel analysis software (TotalLab Ltd., Newcastle upon Tyne, United Kingdom).

\section{Phylogenetic Analysis}

The $16 \mathrm{~S}$ rRNA gene sequence obtained was compared against DNA Databank of Japan (DDBJ) and NCBI via BLAST analysis to retrieve similar sequences (Zhang et al., 2000). A Neighbor joining (NJ) phylogenetic tree was constructed (Saitou and Nei, 1987) using MEGA 7.0 (Kumar et al., 2016) with bootstrap analysis based on 1000 replicates (Felsenstein, 1985). The evolutionary distance was measured using the p-distance method (Nei and Kumar, 2000). Additionally, the banding pattern obtained in ARDRA was scored to generate a dendrogram using the NTSYSpc version 2.02 software. The phylogenetic relationship was determined according to the method of unweighted pair group method with arithmetic mean (UPGMA) (Sokal and Michener, 1958) using DICE similarity coefficient, all the strains were grouped into different phylotypic groups. Similarly, the fingerprints generated during the BOX-PCR were analyzed using Phoretix 1D Pro gel analysis software (TotalLab Ltd., United Kingdom) to obtain a dendrogram according to UPGMA using DICE similarity coefficient. 


\section{Molecular Characterization Chitinase Gene}

The isolates which were positive for chitinase activity in plate assay were subjected to chitinase gene amplification using PCR. Chitinase gene, 18 family PCR amplification was carried out using primers GA1F and GA1R as previously reported (Williamson et al., 2000). The PCR reaction mixture $(10 \mu \mathrm{l}$ total volume) contained $1 \mathrm{X}$ Taq buffer, $0.2 \mu \mathrm{M}$ of each primer, $125 \mu \mathrm{M}$ each dNTP and $0.5 \mathrm{U}$ of Taq polymerase and 10 ng template DNA. The PCR amplification cycle consisted of $5 \mathrm{~min}$ at $94^{\circ} \mathrm{C}, 35$ cycles of $1 \mathrm{~min}$ at $94^{\circ} \mathrm{C}$ and $30 \mathrm{~s}$ at $60^{\circ} \mathrm{C}$, and a final extension of $7 \mathrm{~min}$ at $72^{\circ} \mathrm{C}$ and was carried out in a Mastercycler nexus PCR system (Eppendorf, Germany). The PCR products were subjected to gel electrophoresis using $1.5 \%$ agarose gels stained with $\mathrm{EtBr}(10 \mu \mathrm{g} / \mathrm{mL})$ at $70 \mathrm{~V}$ for $45 \mathrm{~min}$ along with 100bp DNA ladder and visualized using a gel documentation system (ChemiDoc XRS +, BioRad, United States).

\section{Biosynthetic Gene Clusters}

NRPS, PKS I and PKS II gene amplification were carried out using degenerate primers (Ayuso-Sacido and Genilloud, 2005). The PCR cycle consists of $5 \mathrm{~min}$ at $95^{\circ} \mathrm{C}$ and 35 cycles of $30 \mathrm{~s}$ at $95^{\circ} \mathrm{C}, 2 \mathrm{~min}$ at $55^{\circ} \mathrm{C}$ for $\mathrm{K} 1 \mathrm{~F} / \mathrm{M} 6 \mathrm{R}, 59^{\circ} \mathrm{C}$ for $\mathrm{A} 3 \mathrm{~F} / \mathrm{A} 7 \mathrm{R}$ or $58^{\circ} \mathrm{C}$ for $\mathrm{K} 1 \mathrm{~F} / \mathrm{M} 6 \mathrm{R}$ and $\mathrm{A} 3 \mathrm{~F} / \mathrm{A} 7 \mathrm{R}$ and $4 \mathrm{~min}$ at $72^{\circ} \mathrm{C}$, followed by $10 \mathrm{~min}$ at $72^{\circ} \mathrm{C}$. PCR amplified products were analyzed by $1 \%$ agarose gel electrophoresis stained with ethidium bromide and visualized using a gel documentation system (ChemiDoc XRS +, Bio-Rad, United States).

\section{Plant Growth Promoting Experiment in Nursery Condition \\ Plant Sample}

Tea a woody perennial slow growing tree crop, which is commonly propagated through vegetative propagation. Tea crop is mainly propagated through vegetative propagation for maintaining quality in commercial cultivation. The Tocklai tea Research Institute, Jorhat, Assam, India have until now released 33 vegetatively propagated clones (TV series) which are either standard or yield clones for the purpose of commercial cultivation especially in Northeast India. In this study, we selected two standard clones (TV1 and TV9) and two yield clones (TV18 and TV22) available at Betali Tea estate, Assam, India for the PGP experiment in nursery conditions. The TV clones are grown for about 6-7 months of growth in polythene sleeves before they can be transferred to the field. The tea saplings are grown and maintained in polythene sleeves following the standard protocol of sleeve preparation for vegetative propagation of tea (Field Management Notes, TTRI, Jorhat). The commercial tea is grown through vegetative propagation using cuttings. The cuttings are first treated in $0.1 \% \mathrm{ZnSO}_{4}$ solution and planted in nursery beds. After root formation (8-12 weeks), the cuttings are transferred to sleeves containing fine tilth soil obtained by

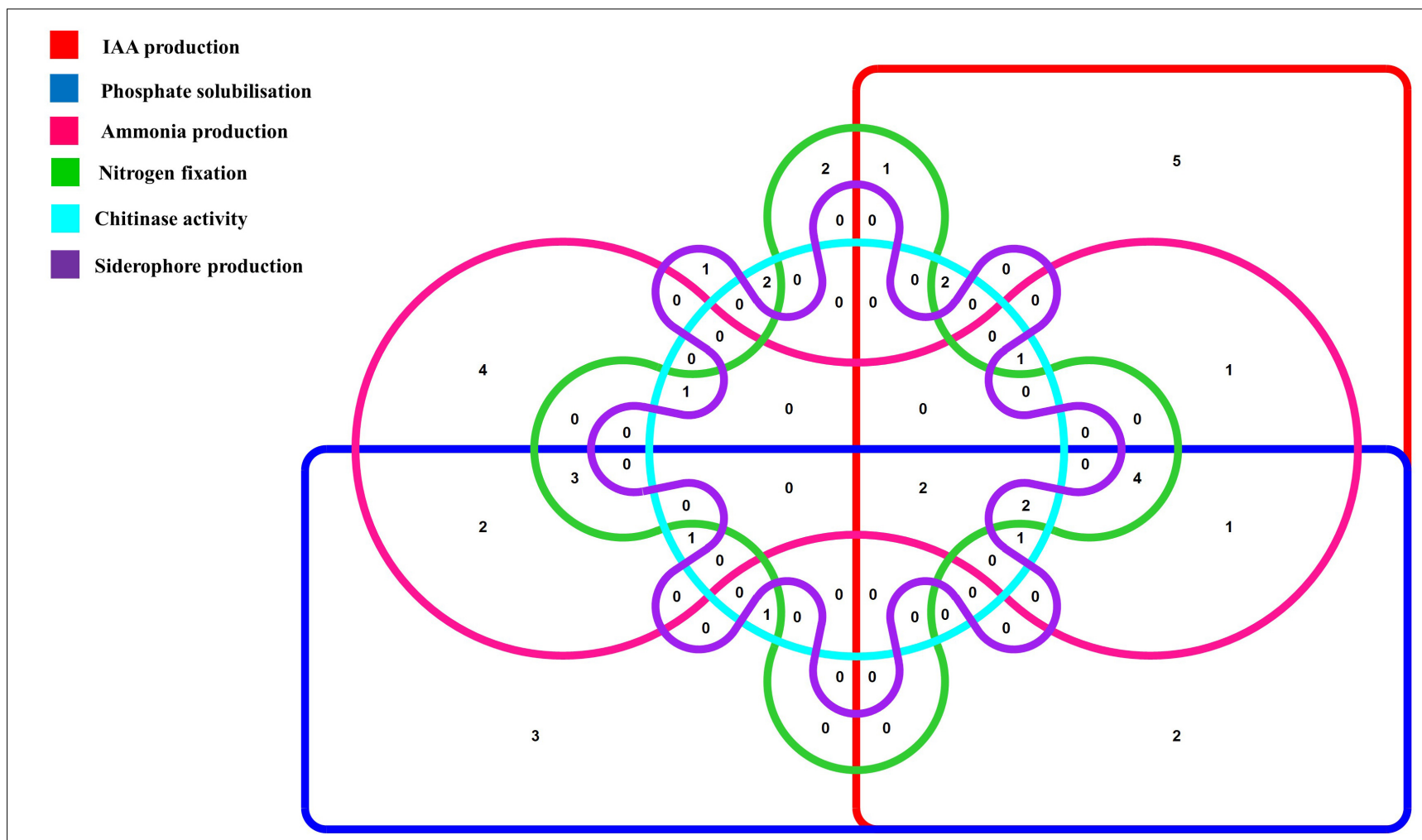

FIGURE 1 | Venn diagram representation of plant growth promoting endophytic actinobacterial isolates showing different PGP traits. The Venn diagram shows the allocation of 46 PGP endophytic actinobacterial isolates into 6 profiles representing 6 PGP traits. 
sieving with G1 wire mesh no. 4 and mixed with phosphate at $500 \mathrm{~g} / \mathrm{m}^{3}$ of soil. The soil used in the sleeves are sandy loam soils maintained within the $\mathrm{pH}$ range of 4.5 to 5.5 (Field Management Notes, TTRI, Jorhat). The size of the sleeve is $17.7 \mathrm{~cm}$ lay flat, $25 \mathrm{~cm}$ long and 150 gauge thick. The cuttings are grown in these sleeves for about 5-6 months and then transferred to the garden (Borah et al., 2019). Four different types of healthy 34 months old TV clones, TV1, TV9, TV18 and TV22 were selected for in vivo PGP experiment and procured from Betali Tea estate, Assam.

TABLE 3 | Extracellular hydrolytic enzyme production by endophytic actinobacteria associated with tea.

\begin{tabular}{|c|c|c|c|c|c|c|}
\hline SI. no. & Strain code & Protease & Pectinase & Cellulase & ACC deaminase & Chitinase \\
\hline 1 & SA1 & + & - & - & + & + \\
\hline 2 & SA2 & + & + & + & - & + \\
\hline 3 & T1LA3 & - & - & + & - & - \\
\hline 4 & SA16 & - & + & - & - & - \\
\hline 5 & SA6 & + & - & - & + & - \\
\hline 6 & CSLA2 & - & - & - & + & - \\
\hline 7 & CJRA1 & - & - & - & - & + \\
\hline 8 & S40 & - & + & + & - & + \\
\hline 9 & SA21 & + & - & - & - & + \\
\hline 10 & SA5 & + & - & - & - & - \\
\hline 11 & CSLA5 & - & - & - & - & - \\
\hline 12 & S51 & + & + & + & + & - \\
\hline 13 & S62 & - & + & + & - & + \\
\hline 14 & S28 & - & + & + & - & - \\
\hline 15 & T1LA5 & - & - & - & - & - \\
\hline 16 & S39 & - & - & + & - & - \\
\hline 17 & SA13 & - & - & - & - & + \\
\hline 18 & SA14 & - & - & - & - & - \\
\hline 19 & SA9 & - & - & - & - & - \\
\hline 20 & S41 & + & - & - & + & - \\
\hline 21 & S85 & + & + & - & + & - \\
\hline 22 & S42 & - & - & - & + & - \\
\hline 23 & SA10 & - & - & - & - & - \\
\hline 24 & SA20 & - & - & - & - & - \\
\hline 25 & S84 & + & + & - & - & - \\
\hline 26 & CJRA5 & - & - & - & - & - \\
\hline 27 & CJRA2 & - & - & + & - & - \\
\hline 28 & CSLA7 & - & - & - & - & - \\
\hline 29 & CRRA1 & - & - & - & - & + \\
\hline 30 & $\mathrm{SA} 7$ & + & - & - & + & - \\
\hline 31 & SA8 & - & - & + & - & + \\
\hline 32 & SA4 & - & - & - & - & - \\
\hline 33 & S43 & - & + & + & - & + \\
\hline 34 & S72 & - & - & - & + & - \\
\hline 35 & CSR1 & + & - & - & - & - \\
\hline 36 & SA27 & + & + & - & + & + \\
\hline 37 & SA35 & - & - & - & - & - \\
\hline 38 & SA17 & + & - & - & - & - \\
\hline 39 & SA12 & + & - & - & - & + \\
\hline 40 & SA29 & - & - & - & + & - \\
\hline 41 & SA3 & - & - & + & + & - \\
\hline 42 & SA25 & + & - & + & + & - \\
\hline 43 & CSR3 & - & - & - & - & - \\
\hline 44 & CSLA6 & + & - & - & - & - \\
\hline 45 & CSR4 & - & - & - & - & - \\
\hline 46 & SA11 & - & - & - & - & - \\
\hline
\end{tabular}

+ Growth or enzyme activity detected; - No growth, or no enzyme activity detected. 


\section{Preparation of Actinobacterial Inoculum and Treatment}

Three potent actinobacterial strains based on the ranking derived from bonitur assessment were considered for the PGP experiment in nursery conditions. The pure actinobacteria isolates were individually inoculated in GLM culture broth and grown at $28^{\circ} \mathrm{C}$ for 7 days under agitated conditions. The culture was centrifuged at $8000 \mathrm{~g}$ for $5 \mathrm{~min}$ and the cell pellet was resuspended in phosphate buffer saline $(\mathrm{pH}$ 7.4). The cell density was adjusted to $10^{8} \mathrm{CFU} / \mathrm{mL}$ at $610 \mathrm{~nm}$ using a spectrophotometer (Singh et al., 2016).

Five treatments including (1) untreated tea saplings as control, (2) treatment 1 (SA1), (3) treatment 2 (T1LA3), (4)

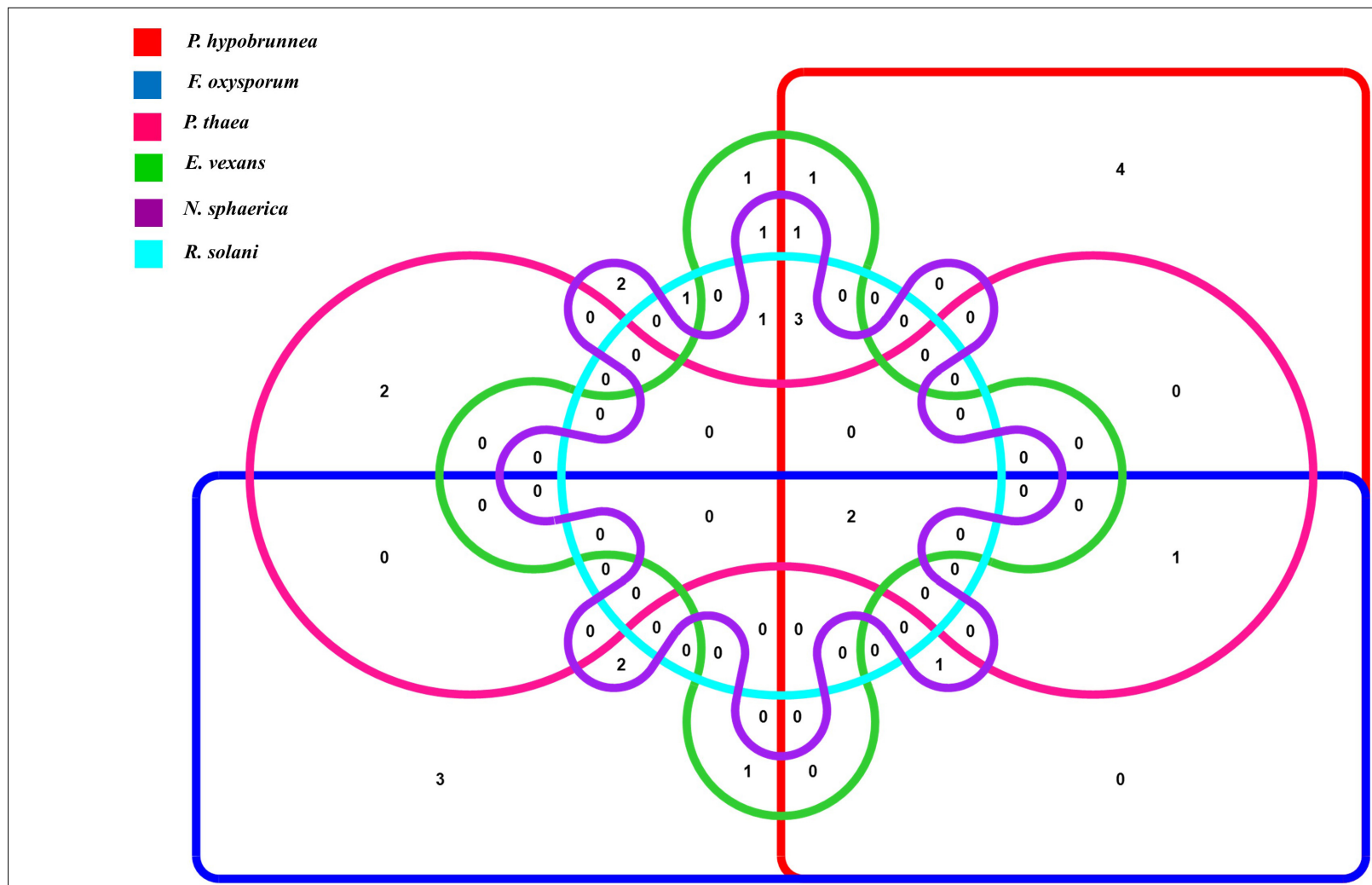

FIGURE 2 | Venn diagram representation of antifungal traits of 46 endophytic actinobacteria isolates showing 6 profiles representing the 6 tested tea phytopathogens.

TABLE 4 | The most potent isolates based on Bonitur ranking of endophytic actinobacteria associated with tea with PGP and biocontrol traits.

\begin{tabular}{|c|c|c|c|c|c|c|c|c|c|c|c|c|c|c|c|c|}
\hline \multirow[t]{2}{*}{ SI. No. } & \multirow[t]{2}{*}{ Strain code } & \multicolumn{6}{|c|}{ Antagonistic activities } & \multicolumn{2}{|c|}{$\begin{array}{l}\text { Antifungal } \\
\text { mechanisms }\end{array}$} & \multicolumn{5}{|c|}{ PGP traits } & \multirow[t]{2}{*}{$\begin{array}{c}\text { Total ass. } \\
(29)^{n}\end{array}$} & \multirow[t]{2}{*}{ Ranking } \\
\hline & & $\mathbf{P h}^{\mathbf{a}}$ & $\mathrm{Fo}^{\mathrm{b}}$ & $\mathrm{Pt}^{\mathrm{C}}$ & $E v^{d}$ & $R s^{e}$ & $\mathrm{Ns}^{\mathrm{f}}$ & $\mathrm{Chi}^{\mathrm{g}}$ & Sid $^{\mathrm{h}}$ & $I^{A} A^{i}$ & PS & $\mathrm{AM}^{\mathrm{k}}$ & $A^{\prime} C^{\prime}$ & $\operatorname{Sid}^{m}$ & & \\
\hline 1 & SA1 & 0 & 0 & 0 & 3 & 3 & 2 & 1 & 1 & 2 & 2 & 1 & 1 & 1 & 17 & $1^{s t}$ \\
\hline 2 & T1LA3 & 3 & 0 & 0 & 3 & 2 & 3 & 0 & 1 & 2 & 0 & 1 & 1 & 1 & 17 & $1^{s t}$ \\
\hline 3 & SA14 & 1 & 0 & 0 & 3 & 2 & 3 & 1 & 0 & 0 & 3 & 1 & 0 & 0 & 14 & $2^{\text {nd }}$ \\
\hline 4 & SA12 & 2 & 0 & 0 & 2 & 0 & 0 & 1 & 0 & 0 & 3 & 1 & 1 & 1 & 11 & $3^{r d}$ \\
\hline 5 & S85 & 2 & 1 & 0 & 0 & 0 & 1 & 0 & 0 & 3 & 3 & 0 & 1 & 0 & 11 & $3^{r d}$ \\
\hline 6 & S43 & 0 & 1 & 0 & 2 & 0 & 0 & 1 & 1 & 2 & 1 & 1 & 1 & 1 & 11 & $3^{r d}$ \\
\hline 7 & $\mathrm{SA} 2$ & 0 & 2 & 0 & 0 & 0 & 3 & 1 & 0 & 2 & 1 & 1 & 0 & 0 & 10 & $4^{\text {th }}$ \\
\hline 8 & SA25 & 1 & 0 & 1 & 1 & 1 & 1 & 0 & 0 & 1 & 3 & 1 & 0 & 0 & 10 & $4^{\text {th }}$ \\
\hline 9 & S62 & 2 & 0 & 0 & 0 & 1 & 0 & 1 & 0 & 2 & 1 & 1 & 0 & 0 & 8 & $5^{\text {th }}$ \\
\hline 10 & SA29 & 2 & 1 & 1 & 0 & 1 & 1 & 0 & 0 & 1 & 0 & 1 & 0 & 0 & 8 & $5^{\text {th }}$ \\
\hline
\end{tabular}

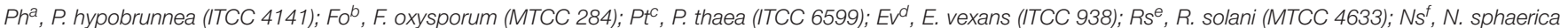

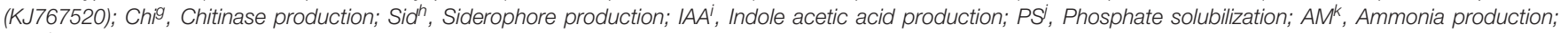
ACC', ACC deaminase production. 
treatment 3 (SA14) (4) consortia (SA1 + T1LA3 + SA14) (five biological replicates for each treatment) were applied to the saplings. Unsterilized soil was used in the experiment to determine the effects of these bacterial strains on tea clones in competition with the naturally occurring soil microbes. The tea clones were treated with $10 \mathrm{ml}$ cell suspension by soil drenching at one-month intervals for three months and watered with sterile distilled water daily (Liotti et al., 2018; Zhao et al., 2018). All vegetative parameters such as shoot length, root length, shoot fresh and dry weight and root fresh, dry weight, chlorophyll content and soil parameter analysis were recorded and compared to control (Dutta et al., 2015b; Dutta and Thakur, 2017).

TABLE 5 | Biochemical profiling of actinobacterial isolates SA1, T1LA3, and SA14 (KB009 HiCarbohydrate kit, Himedia).

\begin{tabular}{|c|c|c|c|c|}
\hline SI. No. & Test & SA1 & T1LA3 & SA14 \\
\hline 1 & Lactose & - & + & - \\
\hline 2 & Xylose & + & + & - \\
\hline 3 & Maltose & + & + & - \\
\hline 4 & Fructose & + & + & + \\
\hline 5 & Dextrose & + & + & + \\
\hline 6 & Galactose & - & - & - \\
\hline 7 & Raffinose & - & - & - \\
\hline 8 & Trehalose & + & + & + \\
\hline 9 & Melibiose & - & + & + \\
\hline 10 & Sucrose & - & + & + \\
\hline 11 & L-Arabinose & - & + & + \\
\hline 12 & Mannose & - & + & - \\
\hline 13 & Inulin & + & - & - \\
\hline 14 & Sodium gluconate & - & - & + \\
\hline 15 & Glycerol & + & + & + \\
\hline 16 & Salicin & + & + & + \\
\hline 17 & Dulcitol & + & + & + \\
\hline 18 & Inositol & - & + & + \\
\hline 19 & Sorbitol & - & + & + \\
\hline 20 & Mannitol & + & + & + \\
\hline 21 & Adonitol & - & + & + \\
\hline 22 & Arabitol & + & + & + \\
\hline 23 & Erythritol & + & + & + \\
\hline 24 & $\alpha$-Methyl-D-glucoside & - & - & - \\
\hline 25 & Rhamnose & + & - & + \\
\hline 26 & Cellobiose & + & + & + \\
\hline 27 & Melezitose & - & + & + \\
\hline 28 & $\alpha$-Methyl-D-mannoside & - & + & + \\
\hline 29 & Xylitol & - & + & + \\
\hline 30 & ONPG & + & + & - \\
\hline 31 & Esculin hydrolysis & + & + & + \\
\hline 32 & D-Arabinose & + & + & - \\
\hline 33 & Citrate utilization & + & + & + \\
\hline 34 & Malonate utilization & + & + & + \\
\hline 35 & Sorbose & - & + & + \\
\hline 36 & Control & - & - & - \\
\hline
\end{tabular}

+ color change or activity detected; - No color change or no activity detected.

\section{Chlorophyll Estimation}

The chlorophyll content in leaf tissues of the treated tea clones with reference to untreated tea clones was determined following the method of Hiscox and Israelstam (2011). Leaf tissue were washed in tap water followed by distilled water and cut into fractions. $100 \mathrm{mg}$ of the cut tissue was placed in vials containing $7 \mathrm{ml}$ of DMSO (HiMedia) and chlorophyll was extracted into the fluid by incubating the vials for $1 \mathrm{~h}$ at $65^{\circ} \mathrm{C}$ without grinding. The extract was transferred to a graduated tube and volume was adjusted to $10 \mathrm{ml}$ with DMSO and absorbance was recorded at $645 \mathrm{~nm}$ and $663 \mathrm{~nm}$. The chlorophyll content was calculated using the following formula:

$$
\begin{aligned}
& \text { Chla }=11.75 \times A 663-2.35 \times A 645 \\
& \text { Chlb }=18.61 \times A 645-3.96 \times A 663
\end{aligned}
$$

\section{Soil Parameter Analysis}

Soil samples from treated and untreated control were collected from 0 to $15 \mathrm{~cm}$, during harvest and sent to Sigma Test and Research Centre, Delhi for soil chemical analysis (Potassium,\% by mass; Organic Matter, $\%$ by mass Total Phosphorus, $\%$ by mass; Available Phosphorus, $\%$ by mass; Total Nitrogen, $\%$ by mass; Available Nitrogen, $\%$ by mass; Sulfur (as So 4 ),\% by mass; Calcium, $\%$ by mass; Magnesium, $\%$ by mass; Water holding capacity, $\%$ by mass; Manganese, mg/kg, Iron, mg/kg; Copper, mg/kg; Zinc, mg/kg; Molybdenum, mg/kg, Boron, mg/kg).

\section{Statistical Analysis}

The data generated through the nursery trial for different growth parameters were subjected to statistical analysis. A two-way Analysis of variance (ANOVA) using the triplicate value between different PGP parameter of treated tea plants compared to the control group for all the clones were assessed. $P \leq 0.05$ was considered statistically significant. Also, principal component analysis (PCA) was done based on the eigen values of a matrix on the PGP datasets to study the correlation between growth parameters and bacterial treatment in the PGP experiment. Furthermore, fold change analysis was done to assess the total value difference between treatment and control averages and the output values are generated in a $\log _{2}$ scale.

\section{RESULTS}

\section{Isolation of Endophytic Actinobacteria}

A total of 46 endophytic actinobacteria were isolated from roots and leaf tissue of five different Camellia spp. and related genera. Morphological characterization of the isolates was recorded (Table 1 and Supplementary Figure 1).

\section{Plant Growth Promoting Traits}

To further characterize the endophytic actinobacterial isolates, their plant growth promoting (PGP) traits were tested (Supplementary Figure 2). The PGP traits of the endophytic 
actinobacteria are summarized in Table 2. Out of 46 strains, 21 (45.6\%) solubilized phosphate at levels ranging from $59.1 \pm 1.6$ to $277.5 \pm 4.8 \mu \mathrm{g} / \mathrm{mL}$ and SA16 solubilized the highest amount of phosphate $(277.5 \pm 4.8 \mu \mathrm{g} / \mathrm{mL})$ among all the isolates. 23 isolates (50\%) out of 46 isolates produced IAA levels in the range $4.4 \pm 0.1$ to $46.5 \pm 0.2 \mu \mathrm{g} / \mathrm{mL}$ among which CJRA1 produced the highest amount of IAA $(46.5 \pm 0.2 \mu \mathrm{g} / \mathrm{mL})$. Ammonia production was shown by 22 isolates in the range 1.3 to $6.5 \mu \mathrm{mol} \mathrm{ml}{ }^{-1}$. T1LA3 isolate showed the highest amount of ammonia production of $6.5 \mu \mathrm{mol} \mathrm{ml}{ }^{-1} .15$ (32.6\%) isolates out of the total isolated endophytic actinobacterial isolates were able to grow on $\mathrm{N}_{2}$ free medium. Siderophore production was showed by 3 isolates out of the total 46 isolates. Two isolates, SA1 and S43 showed all the tested PGP traits, i.e., phosphate solubilization, IAA, ammonia, siderophore and chitinase production (Figure 1).

\section{Extracellular Enzyme Production}

Investigation of hydrolytic enzyme producing ability of the isolates indicated that protease producers were more prevalent among all the isolates (16 isolates, 34.7\%), followed by ACC deaminase producers (13 isolates, $28.2 \%$ ). Cellulase and pectinase production was shown by 12 and 10 strains, respectively. In addition, $12(26.0 \%)$ isolates out of the total isolated endophytic actinobacterial isolates showed chitinolytic activity (Table 3).

\section{Biocontrol Traits}

The antifungal activities of all the strains were tested against six fungal phytopathogens $21(45.6 \%)$ strains showed antifungal activity against at least one of the test pathogens. Altogether, 12 strains inhibited the growth of $P$. hypobrunnea and N. sphaerica each. The growth of E. vexans and F. oxysporum were inhibited by 10 and 9 strains, respectively. The growth of fungal phytopathogen, $P$. theae was inhibited by only 4 isolates. Only two isolates, SA25 and SA29 exhibited broad spectrum antifungal activity against all the tested phytopathogens (Figure 2). In addition, the highest percentage of inhibition was shown by SA21 against $P$. theae $(90 \%)$ followed by T1LA3 against P. hypobrunnea (86.8\%).

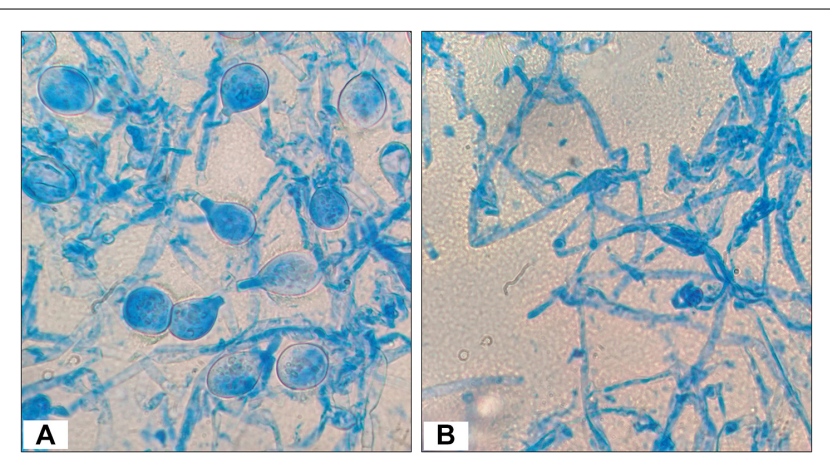

FIGURE 3 | Morphology observations of Poria hypobrunnea (ITCC 4141) mycelia stained with lactophenol cotton blue under light microscope (100X). (A) Fungal mycelia from the control plate and (B) fungal mycelia from the zone of inhibition.

\section{Analysis of PGP and Biocontrol Traits}

An assessment using bonitur scale was done in order to select the most potent endophytic actinobacteria having PGP as well as biocontrol traits (Passari et al., 2016b). In this scale, points were assigned to each PGP and biocontrol traits tested and the maximum possible score is 29 . The maximum point is three given to antifungal activity against each tested pathogen depending on percentage of inhibition, leading to a sum of 18 points. IAA production and phosphate solubilization was each given maximum three points depending on the strength of the PGP traits. Siderophore, ammonia production, chitinase and ACC deaminase were assigned one point each. The top three ranking isolates, SA1, T1LA3, and SA14 were considered for further testing of the efficacy of the endophytic actinobacterial isolates on tea plants in nursery condition (Table 4).

\section{Biochemical Profile of Top Ranked Isolates}

The three highest ranked isolates based on a bonitur scale of ranking, SA1, T1LA3, and SA14 were subjected to biochemical profiling mainly to assess their carbohydrate utilization, $\beta$-galactosidase activity, esculin hydrolysis, citrate and malonate utilization consisting a total of 35 tests. Isolate SA1 showed positive for 18 tests, isolate T1LA3 showed 29 tests and isolate SA14 showed 25 positive tests (Table 5 and Supplementary Figure 2).

\section{Fungal Hyphal Morphology of $P$. hypobrunnea as Affected by Isolate T1LA3}

The test fungal pathogen (control sample) had a homogeneous structure and showed luxurious growth and spore formation. However, the fungal mycelia from the edge of zone of inhibition or interaction showed less extensive growth and no spore formation (Figure 3).

\section{Phosphate Solubilization Efficiency of the Endophytic Actinobacterial Isolates}

The three isolates, SA1, SA14 and S85 were quantitatively tested using colorimetric assay for their efficiency to solubilize phosphate at different initial $\mathrm{pH}$ of $6.0,7.0$ and 8.0 (alkaline, neutral and acidic $\mathrm{pH}$ ). All the isolates were able to grow in the culture medium at all of the initial $\mathrm{pH}$ values studied. The isolates showed higher phosphate solubilization at neutral $\mathrm{pH}$ of 7.0 compared to acidic (6.0) and alkaline $\mathrm{pH}$ (8.0) (Supplementary Table 1).

\section{Confirmation of IAA by TLC, HPLC, and LC-MS}

The production of IAA from endophytic actinobacteria isolates, SA1, T1LA3, and S85 was confirmed by TLC. As shown in Figure 4A, spots separated on TLC plates were observed under UV light at $245 \mathrm{~nm}$ and developed by Salkowski reagent. The results revealed that the putative IAA samples extracted from the isolates and the standard IAA showed similar retention factor 
A

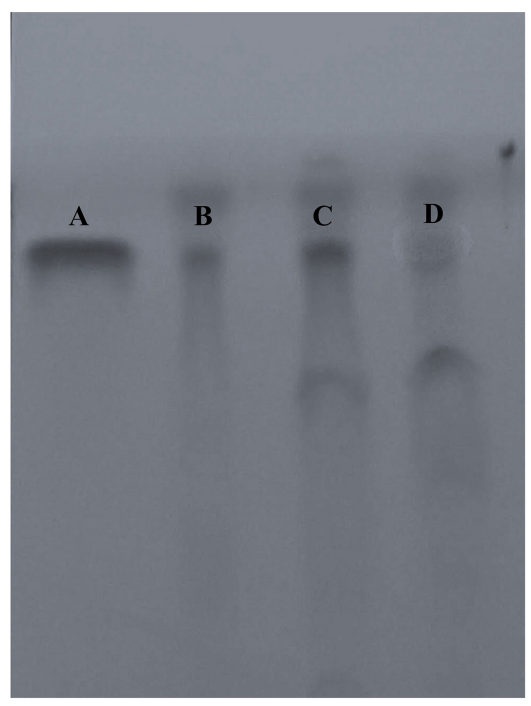

$\mathbf{F}$

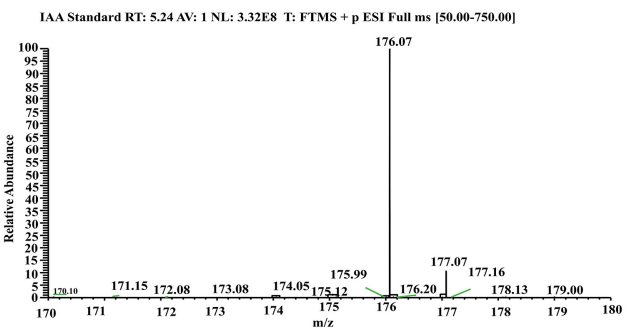

G

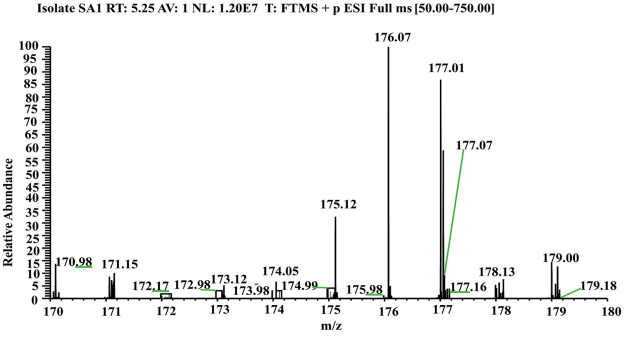

H

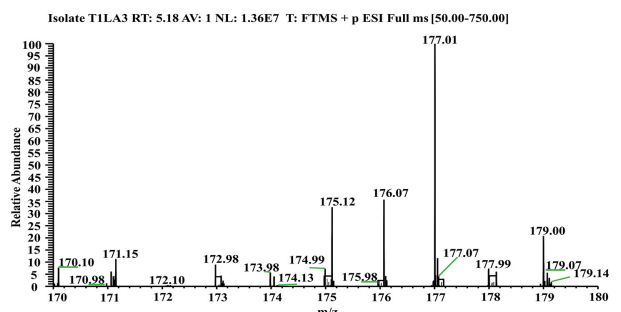

I

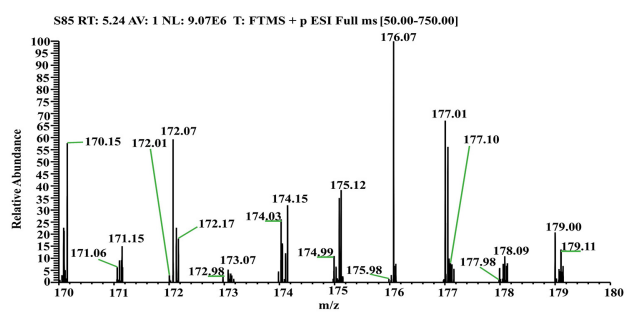

B

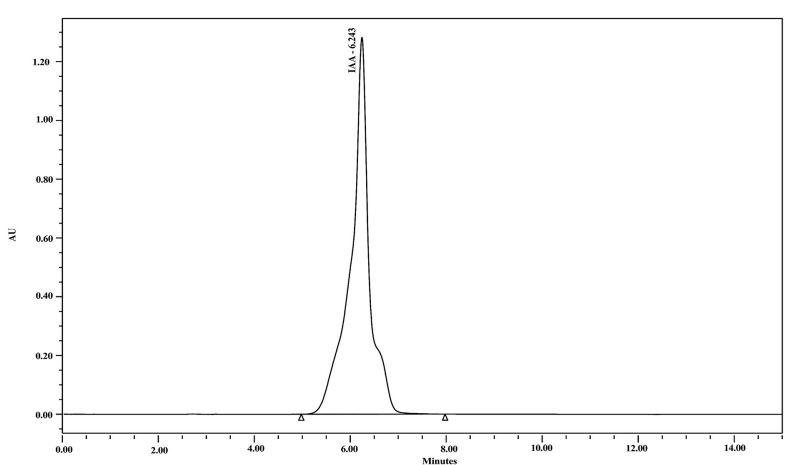

C

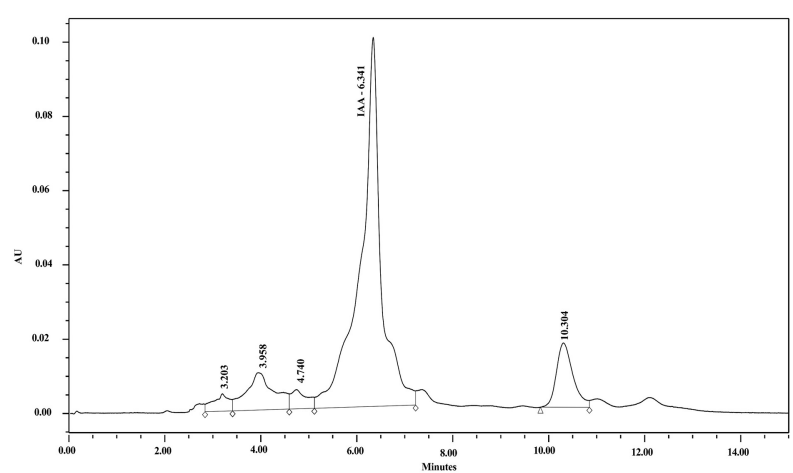

D

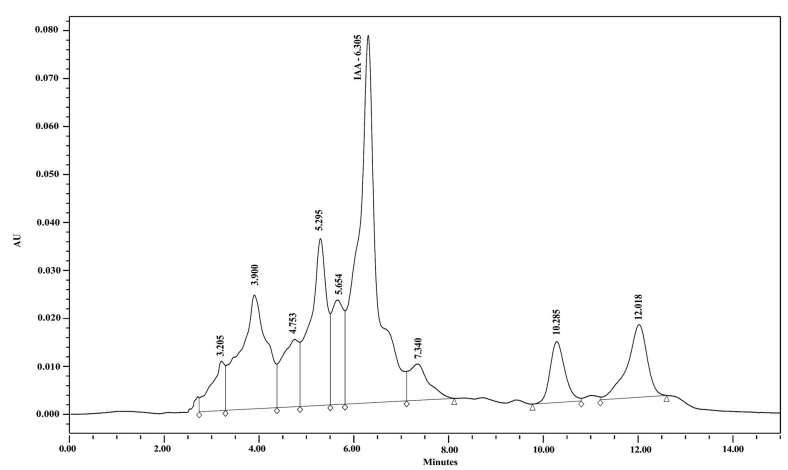

$\mathbf{E}$

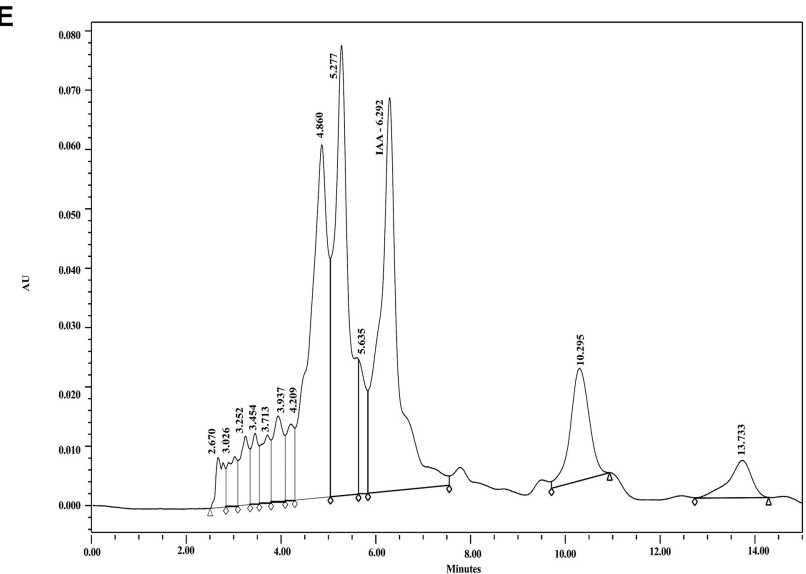

FIGURE 4 | Detection orf IAA production by isolates, SA1, T1LA3, and S85 using chromatographic methods. (A) thin-layer chromatography (TLC) - A. standard IAA, B. SA1, C. T1LA3, and D. S85; High- performance liquid chromatography (HPLC) - (B) standard IAA, (C) SA1, (D) T1LA3, (E) S85; Liquid chromatography-mass spectrometry (LC-MS) - (F) standard IAA, (G) SA1, (H) T1LA3, (I) S85. 


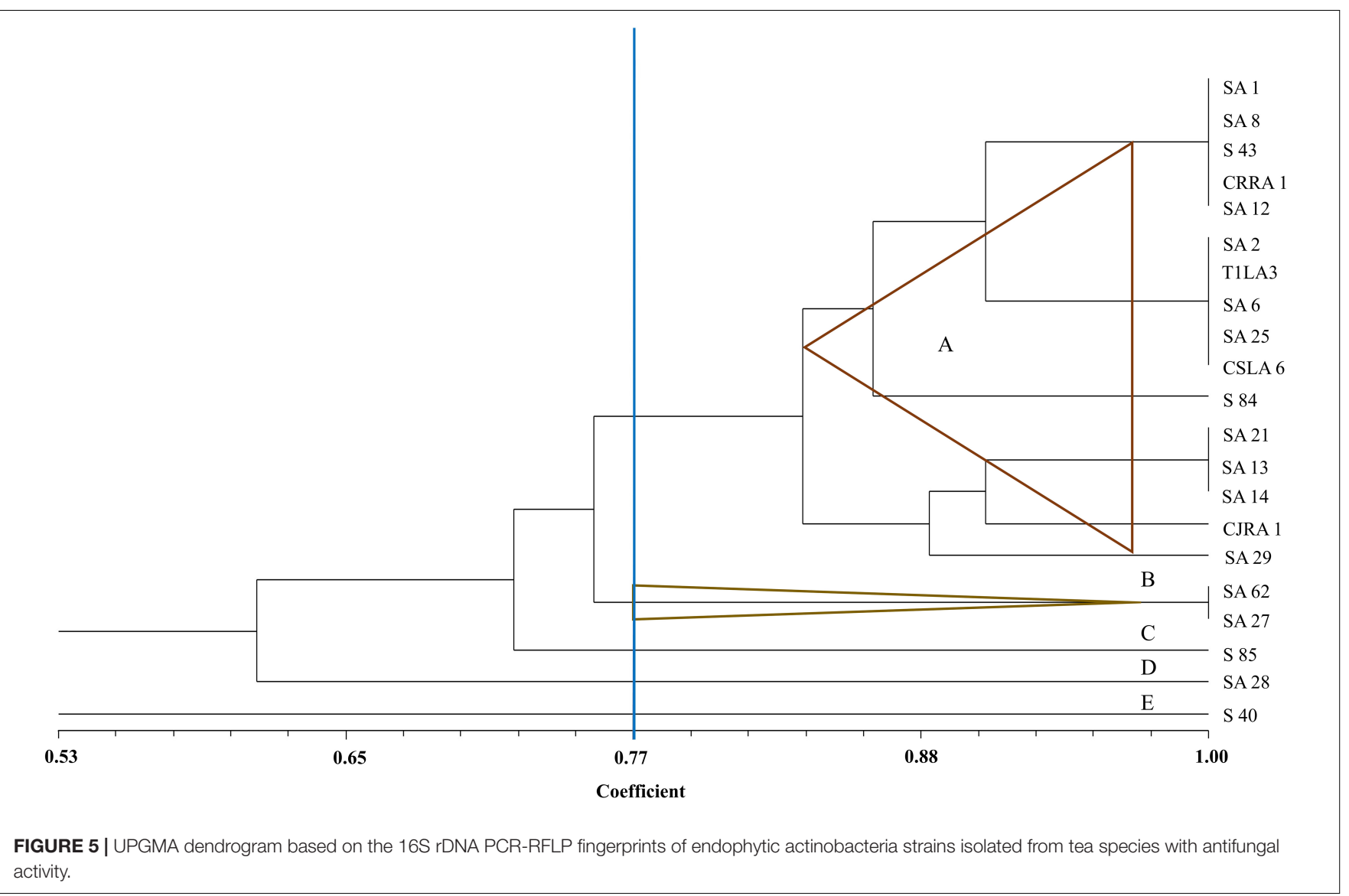

(RF) value of 0.69 . Similarly, the HPLC elution chromatogram of the IAA standard (Sigma) exhibited a major peak at a retention time of $6.243 \mathrm{~min}$, while IAA isolated from SA1 appeared as a sharp peak at a similar retention time of $6.341 \mathrm{~min}$, T1LA3 at $6.305 \mathrm{~min}$, and S85 at $6.292 \mathrm{~min}$ (Figures 4B-E). LC-MS was used to determine more precisely the presence of IAA in the bacterial supernatant of the endophytic actinobacteria isolates SA1, T1LA3, and S85. A solution of standard IAA $(0.5 \mathrm{mg} / \mathrm{mL})$ prepared in methanol was used to determine the retention time of IAA in the LC-MS system (Figures 4F-I). Detection of IAA with positive ionization resulted in a major peak at $\mathrm{m} / \mathrm{z} 176.07$ in extracted ion chromatogram. Using the peak area at m/z 176.07 of the samples, we detected IAA in the supernatants of the isolates, SA1, T1LA3, and S85 (Figures 4F-I).

\section{Diversity of Culturable Endophytic Actinobacteria Associated With Camellia} spp.

\section{ARDRA (Amplified Ribosomal DNA Restriction Analysis) and BOX-PCR Fingerprinting}

The restriction digestion profiles of all the 21 endophytic actinobacteria with antifungal traits were analyzed and a dendrogram was generated. The 21 endophytic actinobacterial strains isolated from 6 different tea species were grouped into 5 separate clusters, A-E at $77 \%$ similarity levels in ARDRA analysis.
The isolates formed one dominant group comprising 16 strains which were divided into subgroups (Figure 5). The other 4 groups contained 1-2 strains. All the Streptomyces spp. were clustered in group A and Microbispora spp. were clustered into group $\mathrm{B}$ on the basis of ARDRA banding patterns. The BOXPCR fingerprinting of all the selected antagonistic endophytic actinobacteria isolates were performed and the bands of sizes between $500 \mathrm{bp}$ to $5 \mathrm{~kb}$ were considered for the scoring to obtain a dendrogram according to UPGMA using DICE similarity coefficient. Analysis of the BOX-PCR fingerprinting showed that the 21 strains were grouped into 4 clusters, A, B, C and D each consisting of 2-8 strains (Figure 6).

\section{$16 S$ rRNA Gene Sequencing}

The 16S rRNA gene sequences of all the endophytic actinobacteria were aligned with $98-100 \%$ similar sequence retrieved from database. The strains belong to the orders Corynebacteriales, Pseudonocardiales, Streptomycetales, Propionibacteriales, Streptosporangiales, and Micrococcales. The majority of the isolates, 28 out of $46(60.8 \%)$ belong to the genus, Streptomyces. The strains represented 9 genera Nocardia, Amycolatopsis, Streptomyces, Pseudonocardia, Kribbella, Actinomadura, Microbispora, Rothia and Saccharomonospora (Table 6). The National Center for Biotechnology Information GenBank accession numbers for the sequences of endophytic actinobacteria are from MH156573 to MH156593, MN337298 


\section{Dendrogram: UPGMA (DICE)}

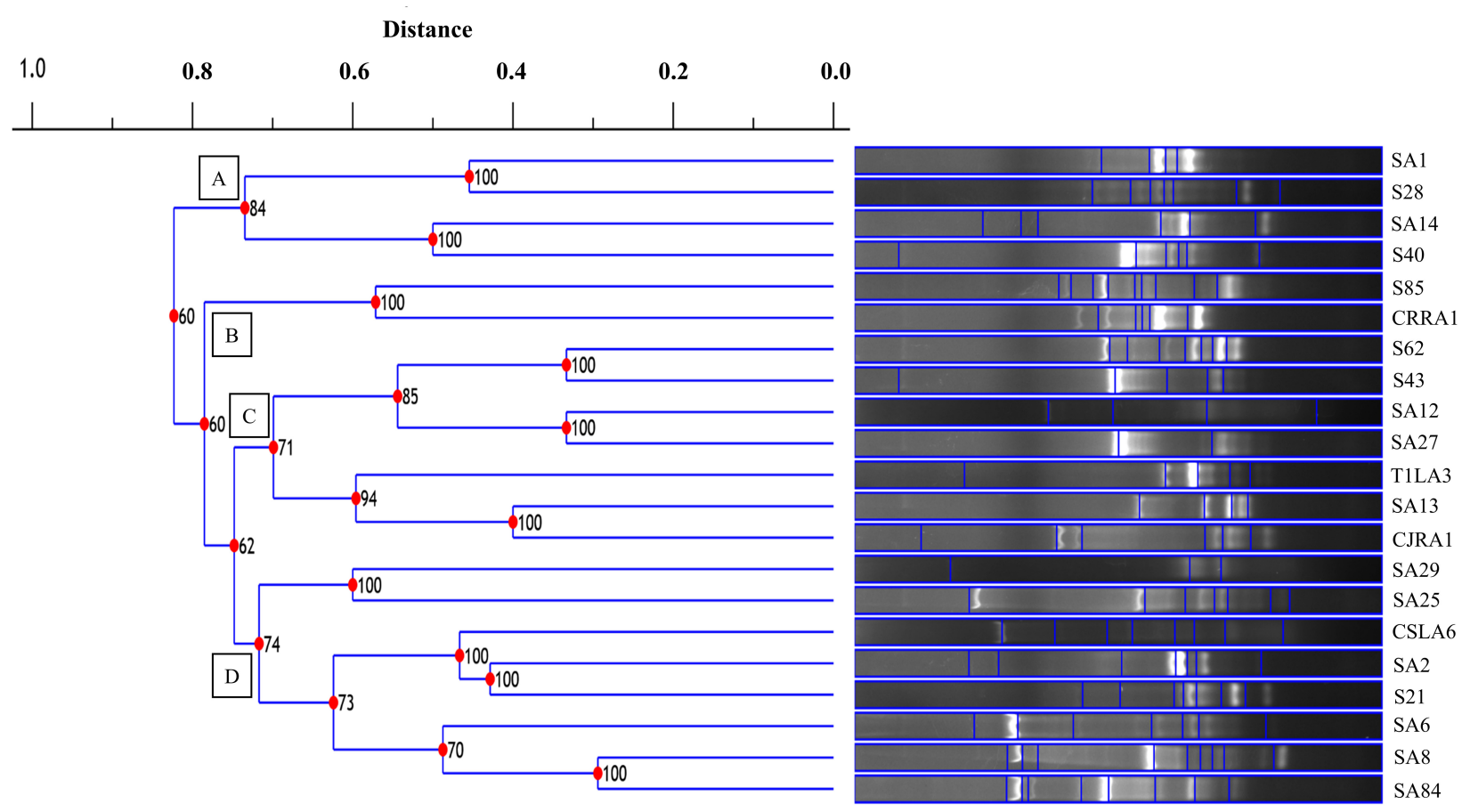

FIGURE 6 | UPGMA dendrogram based on the BOX PCR fingerprints of endophytic actinobacteria strains isolated from tea species with antifungal activity.

to MN337321 and MG779620. The $16 \mathrm{~S}$ rRNA gene sequence of the 21 potent antifungal actinobacteria were aligned with similar sequence to obtain a phylogenetic tree based on NJ method (Figure 7).

\section{Molecular Identification and Detection of Biosynthetic Genes}

Molecular detection of biosynthetic genes revealed that 12 strains out of the 21 potent strains were positive for chitinase 18 Glycosyl Hydrolase family gene. All the isolates showing positive chitinase activity in plate assay were found to be positive for the presence of chitinase 18 Glycosyl Hydrolase family gene. Streptomyces was found to be the major chitinase producing genera with six isolates showing positive for chitinase gene. Also, 11 isolates showed the presence of NRPS gene and one was positive for PKS-1 gene. Strain SA8 Streptomyces sp. is positive for all the biosynthetic genes tested, i.e. chitinase, NRPS and PKS (Supplementary Figure 3).

\section{Tea Plant Growth Promotion by Selected Actinobacterial Isolates}

We further analyzed the efficacy of potent endophytic actinobacterial isolates for PGP in treated plants compared to untreated control plants (Supplementary Figures 4a,b). All the endophytic isolates showed significant differences $(P \leq 0.05)$ in terms of plant growth promoting parameters in the treated plants compared to untreated control. The growth parameters including fresh and dry weight were significantly increased in the treated tea clones (Figure 8). The maximum increase was observed in root dry weight of TV1 clone with treatment 2 (T1LA3) and consortia by 6.2- and 4.05-fold, respectively. However, the degree of PGP in terms of no. of leaves (1.15 to 2.3 fold), shoot dry weight (1.16 to 2.6 fold), root fresh weight (1.0 to 3.3 fold), shoot fresh weight (1.12 to 1.9 fold), shoot height (1.0 to 1.8 fold), root length (1.2 to 1.9 fold) varied with various endophytic actinobacteria treatments in different tea clones (Supplementary Figures 5a-p). The enhancement in the chlorophyll content in actinobacteria treated tea clones signifies their effect on photosynthetic activity and growth of the plant (Figure 8). PCA reduced the various PGP parameters to two principle components, PC1 and PC2 in which PC1 represents the maximum variance in the dataset followed by PC2. More than $75 \%$ of the variation are represented by PC1 in tea clones TV1, TV9 and TV18 and 48\% in TV22. The treatments formed separate groups in all the tea clones showing variance between treated and control groups (Figure 9). In addition, a significant difference in the chlorophyll $\mathrm{a}$ and $\mathrm{b}$ content of the treated tea clones was observed compared to the control group $(P \leq 0.05)$. Soil parameter analysis showed considerable differences in total phosphorus content in TV1 and TV9 tea clones especially when treated with strain SA1. Calcium was not detected in any of the soil samples (Supplementary Tables 2a-d).

\section{DISCUSSION}

Tea is widely used as a beverage due to its medicinal value and caffeine content and has a high economic value 
TABLE 6 | Endophytic actinobacteria isolated from Camellia spp., and the closest type strains based on 16S rRNA gene sequence similarity.

\begin{tabular}{|c|c|c|c|c|c|}
\hline SI. No. & Isolate code & Accession no. & Base pair & Closest hit taxon & Similarity (\%) \\
\hline 1 & SA1 & MN337300 & $1,405 \mathrm{bp}$ & Streptomyces niveus NRRL 2466 & 99.64 \\
\hline 2 & SA2 & MH156574 & $1,405 \mathrm{bp}$ & Streptomyces hyalinus MB891-A1(T) & 99.64 \\
\hline 3 & T1LA3 & $\mathrm{MH} 156575$ & $1,371 \mathrm{bp}$ & Pseudonocardia carboxydivorans Y8 & 99.71 \\
\hline 4 & SA16 & MN337298 & $1,396 \mathrm{bp}$ & Streptomyces camponoticapitis 2H-TWYE14(T) & 99.57 \\
\hline 5 & SA6 & MH156576 & $1,404 \mathrm{bp}$ & Kribbella hippodromi S1.4 & 98.99 \\
\hline 6 & CSLA2 & MN337299 & $1,402 \mathrm{bp}$ & Streptomyces niveus NRRL 2466(T) & 99.64 \\
\hline 7 & CJRA1 & MH156587 & $1,400 \mathrm{bp}$ & Streptomyces diastaticus subsp. Ardesiacus NRRL B-1773 & 100 \\
\hline 8 & S40 & MH156588 & $1,397 \mathrm{bp}$ & Actinomadura rhizosphaerae SDA37 & 98.84 \\
\hline 9 & SA21 & $\mathrm{MH} 156577$ & $1,404 \mathrm{bp}$ & Actinomadura logoneensis NEAU-G17(T) & 98.57 \\
\hline 10 & SA5 & MN337302 & $1,399 \mathrm{bp}$ & Streptomyces sanglieri NBRC 100784 & 99.57 \\
\hline 11 & CSLA5 & MN337303 & $1,395 \mathrm{bp}$ & Streptomyces niveus NRRL 2466 & 99.64 \\
\hline 12 & S51 & MN337304 & $1,406 \mathrm{bp}$ & Streptomyces cyslabdanicus K04-0144 & 99.22 \\
\hline 13 & S62 & MH156578 & $1,399 \mathrm{bp}$ & Microbispora rosea ATCC 12950 & 99.64 \\
\hline 14 & S28 & $\mathrm{MH} 156579$ & $1,394 \mathrm{bp}$ & Nocardia jiangxiensis NBRC 101359 & 98.78 \\
\hline 15 & T1LA5 & MN337317 & $1,359 \mathrm{bp}$ & Streptomyces yanii NBRC 14669 & 98.80 \\
\hline 16 & S39 & MN337305 & $1,396 \mathrm{bp}$ & Nocardia jiangxiensis NBRC 101359 & 99.00 \\
\hline 17 & SA13 & $\mathrm{MH} 156580$ & $1,405 \mathrm{bp}$ & Streptomyces laceyi NRRL 2466 & 99.64 \\
\hline 18 & SA14 & $\mathrm{MH} 156581$ & $1,407 \mathrm{bp}$ & Streptomyces cyslabdanicus K04-0144 & 99.22 \\
\hline 19 & SA9 & MN337316 & $1,406 \mathrm{bp}$ & Streptomyces corchorusii DSM 40340(T) & 98.79 \\
\hline 20 & S41 & MN337313 & $1,397 \mathrm{bp}$ & Streptomyces niveus NRRL 2466 & 99.64 \\
\hline 21 & S85 & MH156582 & $1,396 \mathrm{bp}$ & Nocardia africana DSM 44491 & 99.36 \\
\hline 22 & S42 & MN337307 & $1,388 \mathrm{bp}$ & Streptomyces niveus NRRL 2466 (T) & 99.57 \\
\hline 23 & SA10 & MN337320 & $1,394 \mathrm{bp}$ & Streptomyces kebangsaanensis SUK12 & 99.57 \\
\hline 24 & SA20 & MN337321 & $1,416 \mathrm{bp}$ & Rothia koreensis P31 & 95.39 \\
\hline 25 & S84 & MH156589 & $1,392 \mathrm{bp}$ & Nocardia niigatensis NBRC 100131 & 98.99 \\
\hline 26 & CJRA5 & MN337308 & $1,389 \mathrm{bp}$ & Nocardia Africana DSM 44491 & 99.57 \\
\hline 27 & CJRA2 & MN337309 & $1,399 \mathrm{bp}$ & Nocardia Africana DSM 44491 & 91.97 \\
\hline 28 & CSLA7 & MN337310 & $1,402 \mathrm{bp}$ & Streptomyces niveus NRRL 2466(T) & 99.71 \\
\hline 29 & CRRA1 & MH156590 & $1,394 \mathrm{bp}$ & Actinomadura nitritigenes DSM 44137 & 99.57 \\
\hline 30 & SA7 & MN337311 & $1,379 \mathrm{bp}$ & Streptomyces hyalinus MB891-A1(T) & 99.78 \\
\hline 31 & SA8 & MH156583 & $1,404 \mathrm{bp}$ & Streptomyces pulveraceus LMG 20322 & 99.57 \\
\hline 32 & SA4 & MN337312 & $1,390 \mathrm{bp}$ & Streptomyces niveus NRRL 2466(T) & 99.78 \\
\hline 33 & S43 & $\mathrm{MH} 156584$ & $1,405 \mathrm{bp}$ & Streptomyces sanglieri NBRC 100784 & 99.72 \\
\hline 34 & S72 & MN337315 & $1,405 \mathrm{bp}$ & Streptomyces cyslabdanicus K04-0144 & 99.29 \\
\hline 35 & CSR1 & MN337318 & $1,397 \mathrm{bp}$ & Streptomyces sanglieri NBRC 100784 & 99.64 \\
\hline 36 & SA27 & MH156585 & $1,395 \mathrm{bp}$ & Microbispora rosea ATCC 12950 & 99.78 \\
\hline 37 & SA35 & MN337319 & $1,399 \mathrm{bp}$ & Streptomyces hyalinus MB891-A1(T) & 99.79 \\
\hline 38 & SA17 & MG779620 & $1,399 \mathrm{bp}$ & Streptomyces kebangsaanensis SUK12 & 98.00 \\
\hline 39 & SA12 & $\mathrm{MH} 156591$ & $1,403 \mathrm{bp}$ & Streptomyces camponoticapitis 2H-TWYE14 & 99.43 \\
\hline 40 & SA29 & MH156592 & $1,402 \mathrm{bp}$ & Streptomyces yanii NBRC 14669 & 95.26 \\
\hline 41 & SA3 & $\mathrm{MH} 156573$ & $1,384 \mathrm{bp}$ & Amycolatopsis pretoriensis DSM 44654 & 88.79 \\
\hline 42 & SA25 & $\mathrm{MH} 156586$ & $1,414 \mathrm{bp}$ & Saccharomonospora azurea NA-128 & 99.15 \\
\hline 43 & CSR3 & MN337306 & $1,403 \mathrm{bp}$ & Streptomyces niveus NRRL 2466 & 99.71 \\
\hline 44 & CSLA6 & MH156593 & $1,434 \mathrm{bp}$ & Kribbella hippodromi S1.4 & 98.92 \\
\hline 45 & CSR4 & MN337314 & $1,395 \mathrm{bp}$ & Streptomyces hyalinus MB891-A1(T) & 99.57 \\
\hline 46 & SA11 & MN337301 & $1,412 \mathrm{bp}$ & Kribbella pittospori PIP 158 & 98.59 \\
\hline
\end{tabular}

(Gebrewold, 2018). Like numerous plant species, tea plants host endophytic actinobacteria that are unexplored for microbial natural product discovery. Many previous studies of different host plants have indicated the presence of diverse actinobacteria in plants, including tomato (Fialho de Oliveira et al., 2010), Chinese licorice (Zhao et al., 2018). However, the diversity and function of endophytic actinobacteria in wild Camellia spp. and related genera are not well studied.

Since the endophytic community varies from genera to genera and species to species, sampling plants from different species and genera increases the possibility to isolate different endophytic actinobacteria with varied PGP characteristics. We 


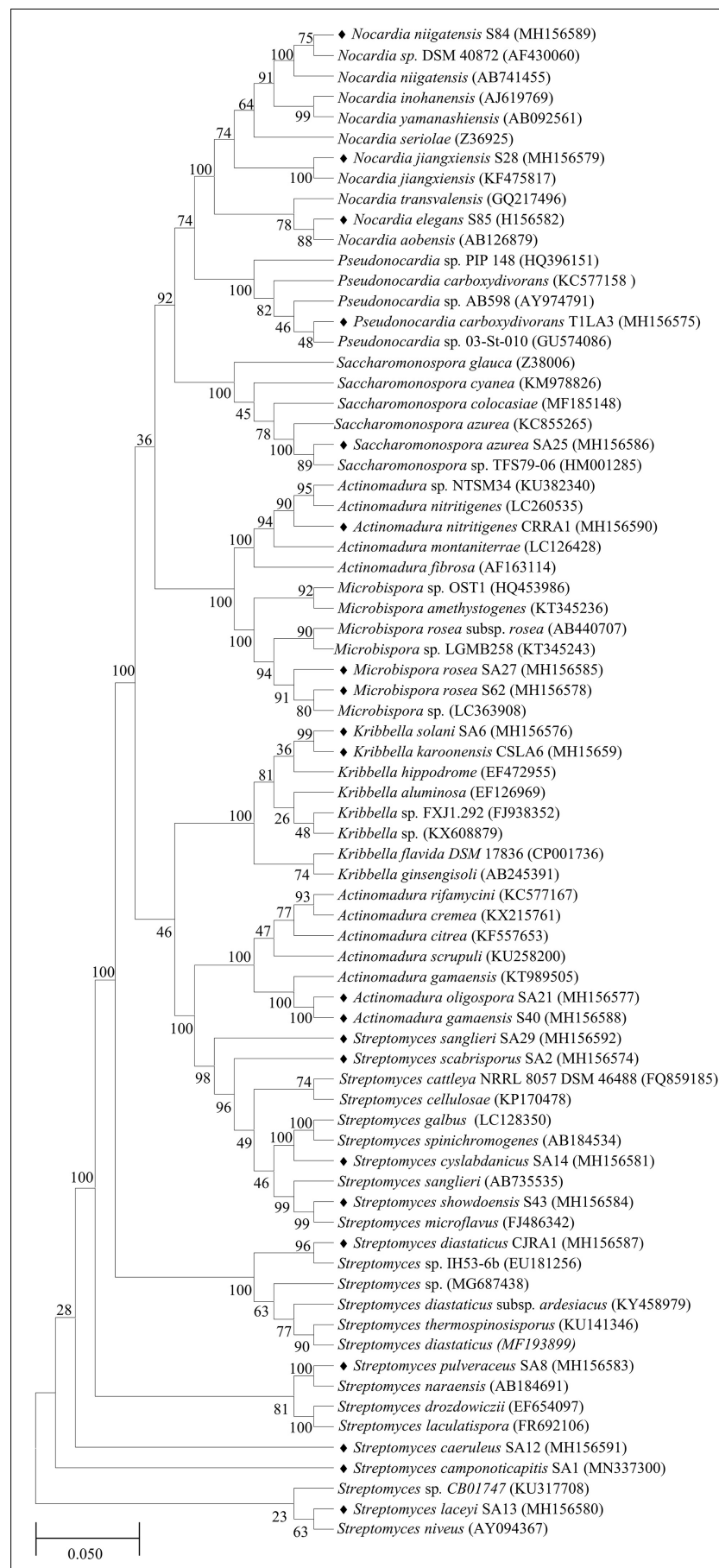

FIGURE 7 | Phylogenetic tree based on NJ method of 16S rRNA gene sequences of endophytic actinobacteria with antifungal activity associated with tea species. The bootstrap consensus tree inferred from 1000 replicates is taken to and branches corresponding to partitions reproduced in less than $50 \%$ bootstrap replicates are collapsed. The percentage of replicate trees in which the associated taxa clustered together in the bootstrap test (1000 replicates) are shown next to the branches. The evolutionary distances were computed using the $\mathrm{p}$-distance method and are in the units of the number of base differences per site. All positions with less than 50\% site coverage were eliminated. That is, fewer than $50 \%$ alignment gaps, missing data, and ambiguous bases were allowed at any position. The scale bar represents 0.05 substitutions per nucleotide position. isolated actinobacteria from the leaves and roots of different Camellia spp. such as C. sinensis, C. japonica, C. sasanqua, C. rosiflora, and C. drupifera, and related genera, Eurya japonica and tested for PGP and antifungal traits. In this study, we isolated nine genera of actinobacteria including Streptomyces and other rare actinobacteria like Nocardia, Amycolatopsis, Pseudonocardia, Kribbella, Actinomadura, Microbispora, Rothia and Saccharomonospora. Most of them have been isolated previously and reported as endophytes from various crops (Hasegawa et al., 2006; Shimizu, 2011; Matsumoto and Takahashi, 2017).

The endophytic actinobacteria associated with plant tissues are capable of promoting plant growth by making nutrients/substrates (e.g., phosphorous, nitrogen and iron) accessible to the host plant, producing various plant hormones and protection from phytopathogens (Liu et al., 2017). In this study, we evaluated different PGP characteristics such as IAA production, phosphate solubilization, ammonia production, siderophore production. Out of 46 endophytic actinobacterial strains associated with Camellia spp., 37 (80.4\%) strains showed at least one PGP or biocontrol trait. Plant growth can be enhanced by the microbial production of phytohormones like IAA which stimulates root elongation and induces the formation of adventitious roots (Sousa and Olivares, 2016). As in previous studies, both Streptomyces and non-Streptomyces spp. were reported as IAA producers and within a similar range (Nimnoi et al., 2010; Shutsrirung et al., 2013; Singh and Dubey, 2018). Phosphorus is a major micronutrient responsible for many functional processes and phosphate solubilizing bacteria (PSB) can increase the availability of phosphorus for the plants. PSB can also increase the accessibility of phosphate in soil by producing hydrolyzing enzymes like acid phosphatase that can hydrolyze inorganic phosphate. As previously reported, a common feature of endophytic actinobacteria is their potential to solubilize inorganic phosphate (Afzal et al., 2019). In the present study, the percentage of total phosphate solubilizers is within the range of previously reported phosphate solubilizers (Qin et al., 2011; Passari et al., 2015), including 14 Streptomyces strains. Biological nitrogen fixation is the mechanism that converts atmospheric nitrogen $\left(\mathrm{N}_{2}\right)$ to ammonia $\mathrm{NH}_{3}$ or $\mathrm{NH}_{4}{ }^{+}$which can be easily used by plants and is carried out by various groups of microbial population (Meena et al., 2017). Nitrogen fixing and ammonia producing bacteria are effective in $\mathrm{N}_{2}$ assimilation, and have been used as inoculants for growth promotion and increasing yield of crops (Marques et al., 2010). Many Streptomyces spp. as well as rare actinobacteria are known to produce ammonia (Nimnoi et al., 2010) and aid in plant growth promotion as reported in this study. Ammonia production is an indirect method of PGP and also plays an important role in suppressing the growth of fungal plant pathogens (Minaxi et al., 2012). Another important trait of the endophytic actinobacteria that influences their PGP and antagonistic activities is the production of iron sequestering molecules, siderophores. In the present investigation only three isolates were able to produce siderophores. Similar results were obtained in Jatropha (Qin et al., 2011). Also, about 28.2\% of the total endophytic actinobacterial isolates were positive ACC deaminase producers. ACC deaminase plays a significant role 

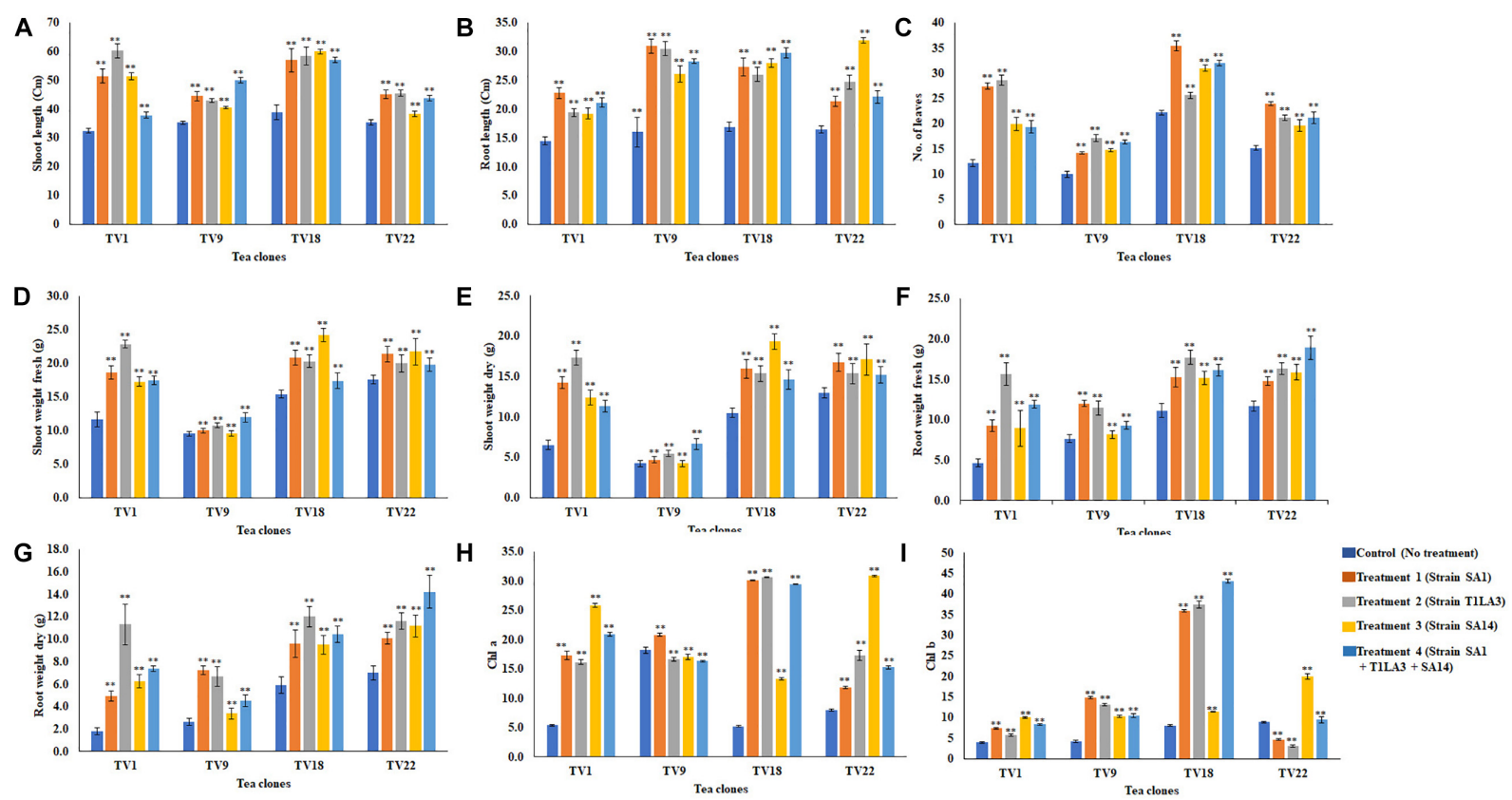

FIGURE 8 | In vivo plant growth promoting effect of endophytic actinobacterial isolates on different commercial clones (TV1, TV9, TV18 and TV22) of tea. (A) Shoot length (cm), (B) root length (cm), (C) No. of leaves, (D) Shoot weight fresh (g), (E) Shoot weight dry (g), (F) Root weight fresh (g), (G) Root weight dry (g), (H) Chlorophyll a (mg/g fresh weight), (I) Chlorophyll b (mg/g fresh weight). The values are mean \pm Standard error $(n=3)$. **Represents statistical significance $(p<0.05$, Two-way ANOVA).

in the reduction of stress ethylene in host plants, thus aiding in withstanding abiotic stress, especially drought (Kang et al., 2010).

Antagonistic microbes that produced hydrolytic enzymes such as cellulase, protease, pectinase and chitinase are capable of degrading fungal and bacterial cell wall, cell membrane, cell membrane proteins, and extracellular virulence factors have been implicated in biocontrol of plant diseases (Palaniyandi et al., 2013). In addition, the production of cell-wall hydrolyzing enzymes, mainly pectinases and cellulases are involved in bacterial entrance and spreading within the plant (Afzal et al., 2019). Most of the isolates screened in this study produced at least one of the extracellular enzymes. Endophytic actinobacteria associated with plants have the ability to minimize the challenges imposed by phytopathogens including the genus, Streptomyces, which is widely recognized for their ability to synthesize numerous bioactive metabolites that play an important role in the phytopathogen control (Sousa and Olivares, 2016; Dinesh et al., 2017). In the present study, Streptomyces and non-Streptomyces species, both showed potent antifungal activity against at least one of the tested fungal phytopathogens. Two isolates SA25 Saccharomonospora sp. and SA29 Streptomyces sp. showed broad spectrum antifungal activity against all the tested pathogens. However, the highest percentage of inhibition was shown by SA21 Actinomadura sp. against $P$. theae followed by SA1 Streptomyces sp. against $R$. solani and T1LA3 Pseudonocardia sp. against $P$. hypobrunnea. In previous studies, many Streptomyces sp. were reported for the synthesis of antifungal metabolites as well as some reports on rare actinobacteria for antimicrobial metabolite production are reported (El-Tarabily et al., 2010;
Palaniyandi et al., 2013; Singh and Dubey, 2018). Endophytic actinobacteria with positive chitinase, NRPS, PKS-1 gene showed antagonistic activity and protected plants against plant phytopathogens (Passari et al., 2016b). Most of the endophytic actinobacteria isolates having antifungal activity were positive for the presence of chitinase, NRPS or PKS-1 gene, suggesting the presence of distinctive mechanisms to inhibit the growth of pathogenic plant fungi. Four isolates were negative for any biosynthetic gene tested in this study which suggests that they might have alternative mechanisms for the inhibition of plant fungal phytopathogens.

In this study, we used the PCR fingerprinting methods, ARDRA and BOX-PCR to document the genetic diversity of the endophytic actinobacterial isolates showing potent antagonistic activity. These 21 isolates were clustered into various groups or clusters. 16S rRNA gene sequencing and BLAST analysis of the total endophytic actinobacterial isolates revealed that the isolates belonged to 9 different genera. Out of the 46 isolates, $28(60.8 \%)$ belonged to genus Streptomyces, 6 (13.0\%) belonged to Nocardia, 3 (6.5\%) belonged to Kribbella and Actinomadura each, 2 (4.3\%) belonged to Microbispora, and 1 (2.1\%) belonged to Amycolatopsis, Pseudonocardia, Saccharomonospora and Rothia each. Streptomyces is the major genus obtained among all the actinobacterial genera. Streptomyces have previously been reported as the most abundant endophytic actinobacterial genera in plants such as Jatropha, wheat, and liquorice (Coombs and Franco, 2003; Qin et al., 2015; Zhao et al., 2018).

Bonitur assessment of the endophytic actinobacteria strains based on their PGP and biocontrol traits revealed SA1, T1LA3, 

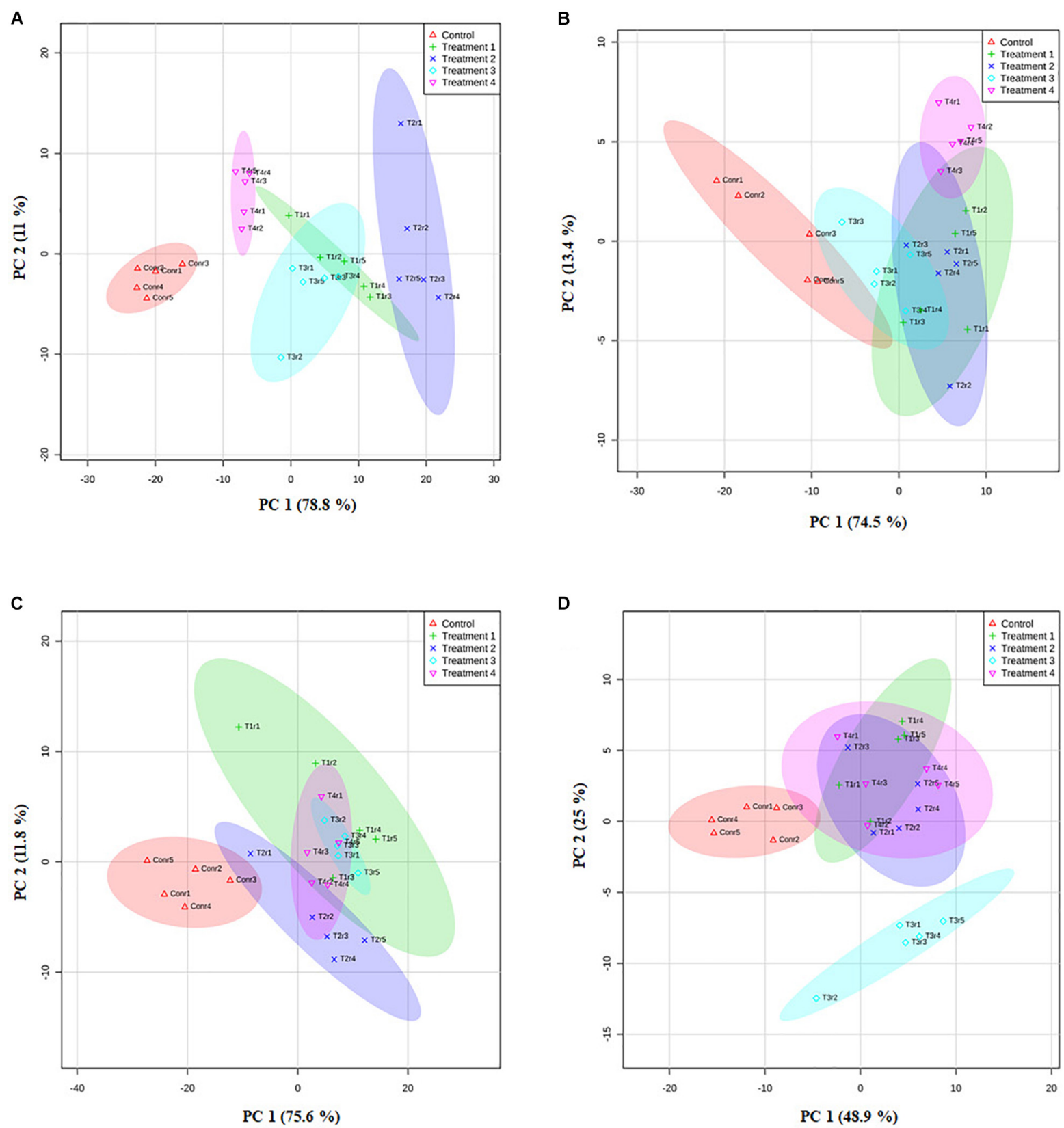

FIGURE 9 | Principle component analysis based on the eigen values in a matrix on the PGP datasets to study the correlation between growth parameters and bacterial treatment in the PGP experiment. (A) TV1, (B) TV9, (C) TV18, and (D) TV22.

SA14, and S85 as the top ranked isolates. These isolates were further tested for their ability to utilize a wide range of substrate based on the principle of $\mathrm{pH}$ change and substrate utilization. All three isolates were able to utilize the substrates, fructose, dextrose, trehalose, glycerol, dulcitol, salicin, mannitol, arabitol, erythritol, cellobiose, esculin, citrate, and malonate. The test fungal pathogen, $P$. hypobrunnea had a homogeneous structure and showed luxurious growth and spore formation compared to the fungal mycelia taken from the edge of the zone of inhibition. Phosphate solubilization efficiency of the isolates in different initial $\mathrm{pH}$ of the broth medium showed that the isolates showed highest phosphate solubilization at neutral $\mathrm{pH}$ by all the three isolates. In our study, the isolates retained their phosphate solubilizing activity at both alkaline and acidic $\mathrm{pH}$. These findings were similar to those reported by Jena and Rath (2013), who reported that the phosphate solubilizing index of the bacterial isolates studied at different $\mathrm{pH}(\mathrm{pH} 4-10)$, maximum solubilizing index (SI) was observed at neutral $\mathrm{pH}(\mathrm{pH} 7.0)$ (Jena and Rath, 2013). Also, isolates SA14 and S85 showed higher phosphate solubilization at alkaline $\mathrm{pH}$ compared to acidic $\mathrm{pH}$. 
Confirmation of IAA production by isolates, SA1, T1LA3 and S85 were done using chromatographic methods. TLC analysis of the ethyl acetate extracts of the samples and standard IAA showed similar RF values, consistent with previous reports (Myo et al., 2019). Furthermore, HPLC analysis of the ethyl acetate extract of the samples showed peaks at similar retention times to those of standard IAA confirming that the isolates were indeed IAA producers. Also, LC-MS analysis of the ethyl acetate extracts with positive ionization resulted in a major peak at $\mathrm{m} / \mathrm{z} 176.07$ in the chromatogram. Using the peak area at $\mathrm{m} / \mathrm{z} 176.07$ of the samples, IAA was detected in the supernatants of the tested isolates.

Endophytic actinobacterial strains with PGP traits are proposed to facilitate growth in host plants through various direct and indirect mechanisms (Afzal et al., 2019). We evaluated the efficacy of three endophytic actinobacterial strains on the growth of $C$. sinensis in a nursery experiment. The strains were selected based on ranking by using a bonitur scale of 29 points. The PGP experiment in this study was performed in commercial nursery condition using non-sterile soil because tea growing soil microbial community is diverse and complex and varies in composition, which represents a real challenge in tea cultivation. The natural microflora associated with the soil are not eliminated in order to test the effect of selected indigenous microbial inoculum compared to the untreated control carried out in 5 replicates in the same condition. The growth of all the inoculated plants in terms of different plant parameters such as fresh and dry biomass was significantly better than the uninoculated control plants. The growth of tea plants in vivo was not directly related to IAA production or phosphate solubilization. Treatment 2 (T1LA3) that produced IAA but didn't solubilize phosphate performed better in TV1 and TV 18 clones, but didn't in TV9 and TV22 clones suggesting that the performance of the PGP strains was possibly dependent on the host plant. The PGP ability of the endophytic bacteria can be shaped by the genotype of the host so that plant colonization and growth promotion ability of the endophytic bacteria seems to be a dynamic process that is structured by the genetic factors of both partners (Afzal et al., 2019).

\section{CONCLUSION}

In conclusion, the endophytic actinobacteria isolated from Camellia spp. and related genera, Eurya, are represented nine different genera of actinobacteria. Most of the strains showed PGP characteristics in vitro, extracellular enzyme production and biocontrol trait against tea phytopathogens. The three strains selected for testing their efficacy in vivo were able to enhance the growth of different tea clones in nursery conditions. These strains were able to utilize a wide range of substrates. The

\section{REFERENCES}

Afzal, I., Shinwari, Z. K., Sikandar, S., and Shahzad, S. (2019). Plant beneficial endophytic bacteria: mechanisms, diversity, host range and genetic determinants. Microbiol. Res. 221, 36-49. doi: 10.1016/j.micres.2019. 02.001 actinobacteria inoculums utilized in this nursery experiment were assumed to have PGP effect, colonization and competent with the other native microbial population. However, interaction of these PGP strains with other native soil microflora and their colonization has to be evaluated in future to establish these strains as biofertilizers. Thus, the endophytic actinobacteria comprising PGP and biocontrol traits which may be deemed potential candidates for sustainable crop production.

\section{DATA AVAILABILITY STATEMENT}

The datasets generated for this study can be found in the GenBank-https://www.ncbi.nlm.nih.gov/nuccore/MG779620, https:/www.ncbi.nlm.nih.gov/nuccore/?term=MN337298: MN337321[accn], and https://www.ncbi.nlm.nih.gov/nuccore/ ?term=MH156573:MH156593[accn].

\section{AUTHOR CONTRIBUTIONS}

DT planned, designed and supervised the research work and guided the experiments. $\mathrm{AB}$ conducted the laboratory and field experiments, acquired and analyzed the data and interpreted the results. $\mathrm{AB}$ and $\mathrm{DT}$ drafted the manuscript.

\section{FUNDING}

This work was partially supported by the Department of Biotechnology (DBT), Govt. of India project (Grant No. BT/BI/12/065/2012).

\section{ACKNOWLEDGMENTS}

The authors thank the Director, Institute of Advanced Study in Science and Technology (IASST), Assam, India, for providing facilities for this work and Department of Science and Technology (DST), Government of India for the fellowship. The authors also like to thank the Institutional Biotech Hub, IASST for providing lab and infrastructure facilities to carry out part of the work.

\section{SUPPLEMENTARY MATERIAL}

The Supplementary Material for this article can be found online at: https://www.frontiersin.org/articles/10.3389/fmicb. 2020.00318/full\#supplementary-material

Ahmad, F., Ahmad, I., and Khan, S. (2005). Indole acetic acid production by the indigenous isolates of Azotobacter and fluorescent Pseudomonas in the presence and absence of tryptophan. Turk. J. Biol. 29, 29-35.

Alexander, D. B., and Zuberer, D. A. (1991). Use of chrome azurol S reagents to evaluate siderophore production by rhizosphere bacteria. Biol. Fertil. Soils. 12, 39-45. doi: 10.1007/BF00369386 
Anjum, S., Xie, X., Wang, L., Saleem, M., Man, C., and Lei, W. (2011). Morphological, physiological and biochemical responses of plants to drought stress. Afr. J. Agric. Res. 6, 2026-2032. doi: 10.5897/AJAR10.027

Ayuso-Sacido, A., and Genilloud, O. (2005). New PCR primers for the screening of NRPS and PKS-I systems in actinomycetes: detection and distribution of these biosynthetic gene sequences in major taxonomic groups. Microb. Ecol. 49, 10-24. doi: 10.1007/s00248-004-0249-6

Bharucha, U., Patel, K., and Trivedi, U. B. (2013). Optimization of indole acetic acid production by Pseudomonas putida UB1 and its effect as plant growthpromoting rhizobacteria on mustard (Brassica nigra). Agric. Res. 2, 215-221. doi: 10.1007/s40003-013-0065-7

Borah, A., Das, R., Mazumdar, R., and Thakur, D. (2019). Culturable endophytic bacteria of Camellia species endowed with plant growth promoting characteristics. J. Appl. Microbiol. 127, 825-844. doi: 10.1111/jam.14356

Cappuccino, J. G., and Sherman, N. (2014). Microbiology: A Laboratory Manual, 10th Edn. London: Pearson.

Coombs, J. T., and Franco, C. M. M. (2003). Isolation and identification of actinobacteria from surface-sterilized wheat roots isolation and identification of actinobacteria from surface-sterilized wheat roots. Appl. Environ. Microbiol. 69, 5603-5608. doi: 10.1128/AEM.69.9.5603

Dinesh, R., Srinivasan, V., Sheeja, T. E., Anandaraj, M., and Srambikkal, H. (2017). Endophytic actinobacteria: diversity, secondary metabolism and mechanisms to unsilence biosynthetic gene clusters. Crit. Rev. Microbiol. 43, 546-566. doi: 10.1080/1040841X.2016.1270895

Dutta, J., Gupta, S., Thakur, D., and Handique, P. J. (2015a). First report of Nigrospora leaf blight on tea caused by Nigrospora sphaerica in India. Plant Dis. 99:417. doi: 10.1094/PDIS-05-14-0545-PDN

Dutta, J., Handique, P. J., and Thakur, D. (2015b). Assessment of culturable tea rhizobacteria isolated from tea estates of Assam, India for growth promotion in commercial tea cultivars. Front. Microbiol. 6:1252. doi: 10.3389/fmicb.2015. 01252

Dutta, J., and Thakur, D. (2017). Evaluation of multifarious plant growth promoting traits, antagonistic potential and phylogenetic affiliation of rhizobacteria associated with commercial tea plants grown in Darjeeling, India. PLoS One 12:e0182302. doi: 10.1371/journal.pone.0182302

Dworkin, M., and Foster, J. W. (1958). Experiments with some microorganisms which utilize ethane and hydrogen. J. Bacteriol. 75, 592-603. doi: 10.1128/jb. 75.5.592-603.1958

El-Tarabily, K. A., Hardy, G. E. S. J., and Sivasithamparam, K. (2010). Performance of three endophytic actinomycetes in relation to plant growth promotion and biological control of Pythium aphanidermatum, a pathogen of cucumber under commercial field production conditions in the United Arab Emirates. Eur. J. Plant Pathol. 128, 527-539. doi: 10.1007/s10658-010-9689-7

Felsenstein, J. (1985). Confidence limits on phylogenies: an approach using the bootstrap. Evolution 39, 783-791. doi: 10.2307/2408678

Fialho de Oliveira, M., Germano da Silva, M., and Van Der Sand, S. T. (2010). Antiphytopathogen potential of endophytic actinobacteria isolated from tomato plants (Lycopersicon esculentum) in southern Brazil, and characterization of Streptomyces sp. R18(6), a potential biocontrol agent. Res. Microbiol. 161, 565-572. doi: 10.1016/j.resmic.2010.05.008

Figueiredo, G. G. O., Lopes, V. R., Fendrich, R. C., and Szilagyi-Zecchin, V. J. (2017). "Interaction between beneficial bacteria and sugarcane," in PlantMicrobe Interactions in Agro-Ecological Perspectives, eds D. Singh, H. Singh, and R. Prabha (Singapore: Springer).

Fiske, C., and Subbarow, Y. (1925). The colorimetric determination of phosphorous. J. Biol. Chem. 66, 375-400. doi: 10.1007/s13398-014-0173-7.2

Gebrewold, A. Z. (2018). Review on integrated nutrient management of tea (Camellia sinensis L.). Cogent Food Agric. 4:1543536. doi: 10.1080/23311932. 2018.1543536

Golinska, P., Wypij, M., Agarkar, G., Rathod, D., Dahm, H., and Rai, M. (2015). Endophytic actinobacteria of medicinal plants: diversity and bioactivity. Antonie van Leeuwenhoek 108, 267-289. doi: 10.1007/s10482-015-0502-7

Gordon, S. A., and Weber, R. P. (1951). Colorimetric estimation of indoleacetic Acid. Plant Physiol. 26, 192-195. doi: 10.1104/pp.26.1.192

Hajiboland, R. (2017). Environmental and nutritional requirements for tea cultivation. Folia Hort. 29, 199-220. doi: 10.1515/fhort-2017-0019

Hasegawa, S., Meguro, A., Shimizu, M., Nishimura, T., and Kunoh, H. (2006). Endophytic Actinomycetes and their interactions with host plants. Actinomycetologica 20, 72-81. doi: 10.3209/saj.20.72
Hayat, K., Iqbal, H., Malik, U., Bilal, U., and Mushtaq, S. (2015). Tea and its consumption: benefits and risks. Crit. Rev. Food Sci. Nutr. 55, 939-954. doi: 10.1080/10408398.2012.678949

Hiscox, J. D., and Israelstam, G. F. (2011). Erratum: a method for the extraction of chlorophyll from leaf tissue without maceration. Can. J. Bot. 57, 1332-1334. doi: 10.1139/b79-163

Hongoh, Y., Yuzawa, H., Ohkuma, M., and Kudo, T. (2003). Evaluation of primers and PCR conditions for the analysis of 16S rRNA genes from a natural environment. FEMS Microbiol. Lett. 221, 299-304. doi: 10.1016/S0378-1097(03) 00218-0

Hsu, S. C., and Lockwood, J. L. (1975). Powdered chitin agar as a selective medium for enumeration of actinomycetes in water and soil. Appl. Microbiol. 29, 422-426. doi: 10.1128/aem.29.3.422-426.1975

Jena, S. K., and Rath, C. C. (2013). Optimization of culture conditions of phosphate solubilizing activity of bacterial sp. isolated from Similipal biosphere reserve in solid-state cultivation by response surface methodology. Int. J. Curr. Microbiol. Appl. Sci. 2, 47-59.

Kang, B. G., Kim, W. T., Yun, H. S., and Chang, S. C. (2010). Use of plant growth-promoting rhizobacteria to control stress responses of plant roots. Plant. Biotechnol. Rep. 4, 179-183. doi: 10.1007/s11816-010-0136-1

Kasana, R. C., Salwan, R., Dhar, H., Dutt, S., and Gulati, A. (2008). A rapid and easy method for the detection of microbial cellulases on agar plates using Gram's iodine. Curr. Microbiol. 57, 503-507. doi: 10.1007/s00284-008-9276-8

Katznelson, H., and Bose, B. (2010). Metabolic activity and phosphate-dissolving capability of bacterial isolates from wheat roots, rhizosphere, and nonrhizosphere soil. Can. J. Microbiol. 5, 79-85. doi: 10.1139/m59-010

Kazanas, N. (1968). Proteolytic activity of microorganisms isolated from freshwater fish. Appl. Microbiol. 16, 128-132. doi: 10.1128/aem.16.1.128-132.1968

Kumar, S., Stecher, G., and Tamura, K. (2016). MEGA7: molecular evolutionary genetics analysis Version 7.0 for bigger datasets. Mol. Biol. Evol. 33, 1870-1874. doi: 10.1093/molbev/msw054

Le, X. H., Franco, C. M. M., Ballard, R. A., and Drew, E. A. (2016). Isolation and characterisation of endophytic actinobacteria and their effect on the early growth and nodulation of lucerne (Medicago sativa L.). Plant Soil 405, 13-24. doi: 10.1007/s11104-015-2652-9

Lee, L., Azman, A., Zainal, N., Eng, S., Mutalib, N., Yin, W., et al. (2014). Microbacterium mangrovi sp. nov., an amylolytic actinobacterium isolated from mangrove forest soil. Int. J. Syst. Evol. Microbiol. 64, 3513-3519. doi: 10.1099/ ijs.0.062414-0

Li, J., Cang, Z., Jiao, F., Bai, X., Zhang, D., and Zhai, R. (2017). Influence of drought stress on photosynthetic characteristics and protective enzymes of potato at seedling stage. J. Saudi Soc. Agric. Sci. 16, 82-88. doi: 10.1016/j.jssas.2015.03.001

Liotti, R. G., da Silva Figueiredo, M. I., da Silva, G. F., de Mendonça, E. A. F., and Soares, M. A. (2018). Diversity of cultivable bacterial endophytes in Paullinia cupana and their potential for plant growth promotion and phytopathogen control. Microbiol. Res. 207, 8-18. doi: 10.1016/j.micres.2017.10.011

Liu, H., Carvalhais, L. C., Crawford, M., Singh, E., Dennis, P. G., Pieterse, C. M. J., et al. (2017). Inner plant values: diversity, colonization and benefits from endophytic bacteria. Front. Microbiol. 8:2552. doi: 10.3389/fmicb.2017.02552

Marques, A. P. G. C., Pires, C., Moreira, H., Rangel, A., and Castro, P. M. L. (2010). Assessment of the plant growth promotion abilities of six bacterial isolates using Zea mays as indicator plant. Soil Biol. Biochem. 42, 1229-1235. doi: 10.1016/j.soilbio.2010.04.014

Marra, L. M., de Oliveira-Longatti, S. M., Soares, C. R. F. S., de Lima, J. M., Olivares, F. L., and Moreira, F. M. S. (2015). Initial pH of medium affects organic acids production but do not affect phosphate solubilization. Braz. J. Microbiol. 46, 367-375. doi: 10.1590/S1517-838246246220131102

Martin, B., Chadwick, W., Yi, T., Park, S. S., Lu, D., and Ni, B. (2012). Vennture - A novel Venn diagram investigational tool for multiple pharmacological dataset analysis. PLoS One 7:e36911. doi: 10.1371/journal.pone.0036911

Matsumoto, A., and Takahashi, Y. (2017). Endophytic actinomycetes: promising source of novel bioactive compounds. J. Antibiot. 70, 514-519. doi: 10.1038/ja. 2017.20

Meena, M., Swapnil, P., Zehra, A., Aamir, M., Dubey, M., Goutam, J., et al. (2017). "Beneficial microbes for disease suppression and plant growth promotion," in Plant-Microbe Interactions in Agro-Ecological Perspectives, eds D. P. Singh, H. B. Singh, and R. Prabha (Singapore: Springer).

Minaxi, N. L., Yadav, R. C., and Saxena, J. (2012). Characterization of multifaceted Bacillus sp. RM-2 for its use as plant growth promoting bioinoculant for crops 
grown in semi-arid deserts. Appl. Soil. Ecol. 59, 124-135. doi: 10.1016/j.apsoil. 2011.08.001

Mondal, T. K., Bhattacharya, A., Laxmikumaran, M., and Ahuja, P. (2004). Recent advances of tea (Camellia sinensis) biotechnology. Plant Cell Tissue Organ Cult. 76, 195-254. doi: 10.1186/1471-2164-12-131

Mukhopadhyay, M., and Mondal, T. K. (2017). "Cultivation, improvement, and environmental impacts of tea," in Oxford Research Encyclopedia of Environmental Science (Oxford: Oxford University Press), 1-26. doi: 10.1093/ acrefore/9780199389414.013.373

Myo, E. M., Ge, B., Ma, J., Cui, H., Liu, B., Shi, L., et al. (2019). Indole-3-acetic acid production by Streptomyces fradiae NKZ-259 and its formulation to enhance plant growth. BMC Microbiol. 19:155. doi: 10.1186/s12866-019-1528-1

Nath, R., Sharma, G. D., and Barooah, M. (2015). Plant growth promoting endophytic fungi isolated from tea (Camellia sinensis) shrubs of Assam, India. Appl. Ecol. Environ. Res. 13, 877-891. doi: 10.15666/aeer/1303_877891

Nei, M., and Kumar, S. (2000). Molecular Evolution and Phylogenetics. Oxford: Oxford University Press.

Nimnoi, P., Pongsilp, N., and Lumyong, S. (2010). Endophytic actinomycetes isolated from Aquilaria crassna Pierre ex Lec and screening of plant growth promoter's production. World J. Microbiol. Biotechnol. 26, 193-203. doi: 10. 1007/s11274-009-0159-3

Onofre-Lemus, J., Hernández-Lucas, I., Girard, L., and Caballero-Mellado, J. (2009). ACC (1-aminocyclopropane-1-carboxylate) deaminase activity, a widespread trait in Burkholderia species, and its growth-promoting effect on tomato plants. Appl. Environ. Microbiol. 75, 6581-6590. doi: 10.1128/AEM. 01240-09

Pal, R. B., and Gokarn, K. (2010). Siderophores and pathogenecity of microorganisms. J. Biosci. Technol. 1, 127-134.

Palaniyandi, S. A., Yang, S. H., Zhang, L., and Suh, J. W. (2013). Effects of actinobacteria on plant disease suppression and growth promotion. Appl. Microbiol. Biotechnol. 97, 9621-9636. doi: 10.1007/s00253-013-5206-1

Passari, A. K., Chandra, P., Zothanpuia, Mishra, V. K., Leo, V. V., Gupta, V. K., et al. (2016a). Detection of biosynthetic gene and phytohormone production by endophytic actinobacteria associated with Solanum lycopersicum and their plant growth promoting effect. Res. Microbiol. 167, 692-705. doi: 10.1016/j.resmic. 2016.07.001

Passari, A. K., Mishra, V. K., Gupta, V. K., Yadav, M. K., Saikia, R., and Singh, B. P. (2015). In vitro and in vivo plant growth promoting activities and DNA fingerprinting of antagonistic endophytic actinomycetes associates with medicinal plants. PLoS One 10:e0139468. doi: 10.1371/journal.pone.0139468

Passari, A. K., Mishra, V. K., Leo, V. V., Gupta, V. K., and Singh, B. P. (2016b). Phytohormone production endowed with antagonistic potential and plant growth promoting abilities of culturable endophytic bacteria isolated from Clerodendrum colebrookianum Walp. Microbiol. Res. 193, 57-73. doi: 10.1016/j. micres.2016.09.006

Patel, J. K., Madaan, S., and Archana, G. (2018). Antibiotic producing endophytic Streptomyces spp. colonize above-ground plant parts and promote shoot growth in multiple healthy and pathogen-challenged cereal crops. Microbiol. Res. 215, 36-45. doi: 10.1016/j.micres.2018.06.003

Qin, S., Miao, Q., Feng, W. W., Wang, Y., Zhu, X., Xing, K., et al. (2015). Biodiversity and plant growth promoting traits of culturable endophytic actinobacteria associated with Jatropha curcas L. growing in Panxi dry-hot valley soil. Appl. Soil. Ecol. 93, 47-55. doi: 10.1016/j.apsoil.2015.04.004

Qin, S., Xing, K., Jiang, J. H., Xu, L. H., and Li, W. J. (2011). Biodiversity, bioactive natural products and biotechnological potential of plant-associated endophytic actinobacteria. Appl. Microbiol. Biotechnol. 89, 457-473. doi: 10.1007/s00253010-2923-6

Saitou, N., and Nei, M. (1987). The neighbor-joining method: a new method for reconstructing phylogenetic trees. Mol. Biol. Evol. 4, 406-425. doi: 10.1093/ oxfordjournals.molbev.a040454

Sathya, A., Vijayabharathi, R., and Gopalakrishnan, S. (2017). Plant growthpromoting actinobacteria: a new strategy for enhancing sustainable production and protection of grain legumes. 3 Biotech 7:102. doi: 10.1007/s13205-0170736-3

Schulz, B., Wanke, U., Draeger, S., and Aust, H. J. (1993). Endophytes from herbaceous plants and shrubs: effectiveness of surface sterilization methods. Mycol. Res. 97, 1447-1450. doi: 10.1016/S0953-7562(09)80215-3

Schwyn, B., and Neilands, J. B. (1987). Universal chemical assay for the detection and determination of siderophores.
Anal. Biochem. 160, 47-56. doi: 10.1016/0003-2697(87)90

612-9

Shimizu, M. (2011). "Endophytic actinomycetes: biocontrol agents and growth promoters," in Bacteria in Agrobiology: Plant Growth Responses, ed. D. Maheshwari (Berlin: Springer), 201-220. doi: 10.1007/978-3-642-20332-9_10

Shirling, E. B., and Gottlieb, D. (1966). Methods for characterization of Streptomyces species. Int. J. Syst. Bacteriol. 16, 313-340. doi: 10.1099/0020771316-3-313

Shutsrirung, A., Chromkaew, Y., Pathom-Aree, W., Choonluchanon, S., and Boonkerd, N. (2013). Diversity of endophytic actinomycetes in mandarin grown in northern Thailand, their phytohormone production potential and plant growth promoting activity. Soil Sci. Plant Nutr. 59, 322-330. doi: 10.1080/ 00380768.2013.776935

Singh, R., and Dubey, A. K. (2018). Diversity and applications of endophytic actinobacteria of plants in special and other ecological niches. Front. Microbiol. 9:1767. doi: 10.3389/fmicb.2018.01767

Singh, S. P., Gupta, R., Gaur, R., and Srivastava, A. K. (2016). Streptomyces spp. alleviate Rhizoctonia solani-mediated oxidative stress in Solanum lycopersicon. Ann. Appl. Biol. 168, 232-242. doi: 10.1111/aab.12259

Smith, N. C., Hennessy, J., and Stead, D. E. (2001). Repetitive sequence-derived PCR profiling using the BOX-A1R primer for rapid identification of the plant pathogen Clavibacter michiganensis subspecies sepedonicus. Eur. J. Plant. Pathol. 107, 739-748. doi: 10.1023/A:1011955811847

Sokal, R. R., and Michener, C. D. (1958). A statistical method for evaluating systematic relationships. Univ. Kansas Sci. Bull. 28, 1409-1438.

Sousa, J. A. D. J., and Olivares, F. L. (2016). Plant growth promotion by Streptomycetes: ecophysiology, mechanisms and applications. Chem. Biol. Technol. Agric. 3:24. doi: 10.1186/s40538-016-0073-5

Teather, R. M., and Wood, P. J. (1982). Use of Congo red-polysaccharide interactions in enumeration and characterization of cellulolytic bacteria from the bovine rumen. Appl. Environ. Microbiol. 43, 777-780. doi: 10.1128/aem.43. 4.777-780.1982

Vijayabharathi, R., Gopalakrishnan, S., Sathya, A., Srinivas, V., and Sharma, M. (2018). Deciphering the tri-dimensional effect of endophytic Streptomyces sp. on chickpea for plant growth promotion, helper effect with Mesorhizobium ciceri and host-plant resistance induction against Botrytis cinerea. Microb. Pathog. 122, 98-107. doi: 10.1016/j.micpath.2018.06.019

Williams, S. T., and Cross, T. (1971). "Actinomycetes," in Methods Microbiol, ed. C. Booth (London: Academic Press), 295-334.

Williamson, N., Brian, P., and Wellington, E. M. H. (2000). Molecular detection of bacterial and streptomycete chitinases in the environment. Antonie van Leeuwenhoek 78, 315-321. doi: 10.1023/A:1010225909148

Yoolon, S., Kruasuwan, W., Pham, H., Jaemsaeng, R., Jantasuriyarat, C., and Thamchaipenet, A. (2019). Modulation of salt tolerance in Thai jasmine rice (Oryza sativa L. cv. KDML105) by Streptomyces venezuelae ATCC 10712 expressing ACC deaminase. Sci. Rep. 9:1275. doi: 10.1038/s41598-018-37 987-5

Zhang, Y., Yu, X., Zhang, W., Lang, D., Zhang, X., Cui, G., et al. (2019). Interactions between endophytes and plants: beneficial effect of endophytes to ameliorate biotic and abiotic stresses in plants. J. Plant Biol. 62, 1-13. doi: 10.1007/s12374018-0274-5

Zhang, Z., Schwartz, S., Wagner, L., and Miller, W. (2000). A greedy algorithm for aligning DNA sequences. J. Comput. Biol. 7, 203-214. doi: 10.1089/ 10665270050081478

Zhao, K., Li, J., Zhang, X., Chen, Q., Liu, M., Ao, X., et al. (2018). Actinobacteria associated with Glycyrrhiza inflata Bat. are diverse and have plant growth promoting and antimicrobial activity. Sci. Rep. 8:13661. doi: 10.1038/s41598018-32097-8

Conflict of Interest: The authors declare that the research was conducted in the absence of any commercial or financial relationships that could be construed as a potential conflict of interest.

Copyright (C) 2020 Borah and Thakur. This is an open-access article distributed under the terms of the Creative Commons Attribution License (CC BY). The use, distribution or reproduction in other forums is permitted, provided the original author(s) and the copyright owner(s) are credited and that the original publication in this journal is cited, in accordance with accepted academic practice. No use, distribution or reproduction is permitted which does not comply with these terms. 